\title{
A VISION FOR A ROBUST GLOBAL STOCKTAKE
}

YAMIDE DAGNET, NOËMIE LEPRINCE-RINGUET, JEMIMA MARIE MENDOZA, AND JOE THWAITES

WORLD

RESOURCES INSTITUTE
(3) climateworks






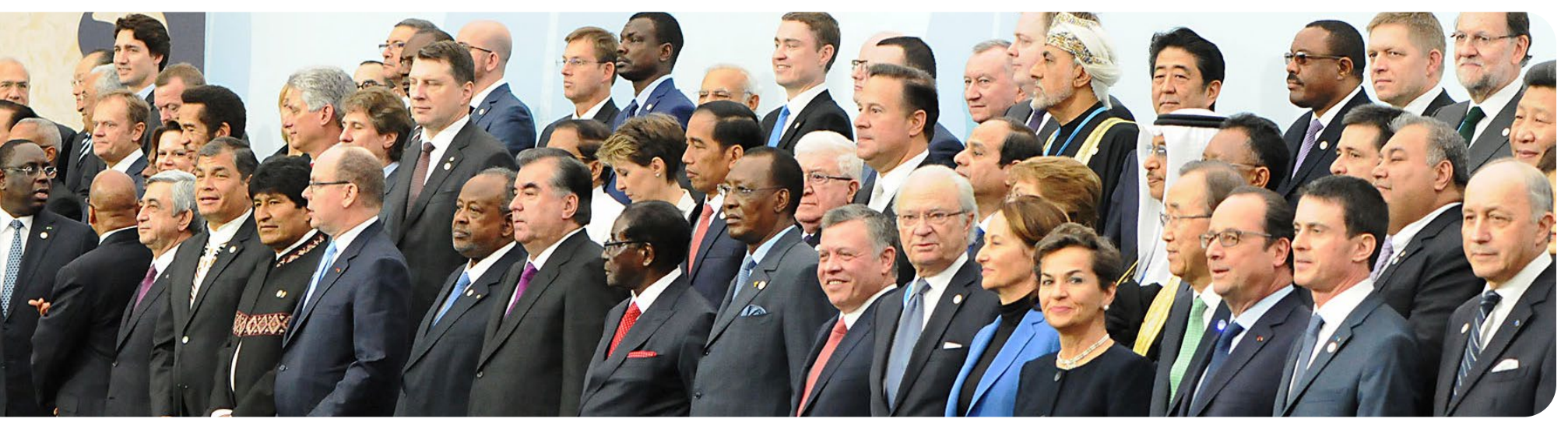

\section{CONTENTS}

2 Executive summary

$7 \quad$ Introduction

10 What has already been decided about the GST?

11 Core functions of an effective GST

13 Process gaps in the GST and suggestions for improvement
Information gaps and uncertainties in the GST and suggestions for improvement

\section{Conclusion}

Appendix A. Timeline of the first GST

Appendix B. Possible guiding questions for the GST

Appendix C. Matching suggestions for an effective GST to the GST's components

Abbreviations

Endnotes

References

Acknowledgments

About the authors

\section{EXECUTIVE SUMMARY}

\section{Highlights}

- The Global Stocktake (GST) is a core mechanism of the Paris Agreement, essential to fulfilling its long-term goals on mitigation, adaptation, and finance. It was created to review collective efforts and increase climate action, support, and international cooperation.

- While the implementing guidelines adopted at COP24 in Katowice, Poland, in 2018 provide an essential foundation, the GST process can still be strengthened and refined during its preparation period before its first cycle from 2022 to 2023, so that it works as an effective enhancement mechanism for climate action and support.

- This issue brief explores how the GST can best be operationalized to fulfil four expected core functions identified in this issue brief: pace-setting, driving ambition, holding countries accountable, and sending implementation signals to reach the Paris Agreement's mitigation, adaptation, and financial goals.

- In order to achieve the Paris Agreement's goals in accordance with science and equity, this issue brief suggests ways to address existing gaps and make the GST more effective, both to strengthen the process and to make the consideration of content more robust.

- This issue brief also highlights how countries and non-state stakeholders, after completion of the GST, can build support for translating its outputs into enhanced climate action, support, and international cooperation. 


\section{Introducing the Global Stocktake}

The Global Stocktake (GST) is a process established under the Paris Agreement (PA) to periodically take stock of collective progress toward achieving the purpose and long-term goals of the PA. The GST's objective is to "inform Parties to the Paris Agreement in updating and enhancing, in a nationally determined manner, their action and support in accordance with the relevant provisions of the Agreement, as well as enhancing international cooperation for climate action." This makes the GST a key component of the Paris architecture in support of the ambition cycle. The first GST will take place from 2022 to 2023 and every five years thereafter. This exercise can provide a thorough diagnosis of the collective progress made toward a climate-safe world and identify opportunities for countries to enhance climate action and support.

In 2018, the Parties negotiated the core structure of the GST at the 24th Conference of the Parties to the United Nations Framework Convention on Climate Change (COP24) in Katowice, Poland. According to that decision, the GST process will be conducted in three stages, starting with an "information collection and preparation" component, followed by a "technical assessment" component, and concluding with a "consideration of outputs" component. Information will be gathered and synthesized in the first component, and collective progress will be assessed in the second component. The third and final component is the most politically challenging and consequential as it will largely determine how the GST informs and motivates the revision and enhancement of countries' climate actions and support and the strengthening of international cooperation. The GST mandate consists of taking stock of progress toward the long-term goals of the PA as defined in Article 2.1 $(\mathrm{a}-\mathrm{c})$. The stocktaking exercise is mandated to consider the thematic areas of mitigation, adaptation, and means of implementation and support, together with efforts that address loss and damage and response measures.

The elements of the GST process and details of the substantive information to be considered still need to be fleshed out. This is vital to ensure that the GST delivers on its mandate and informs more ambitious climate action, support, and international cooperation. Elaboration is also critical if the GST is to fulfil the four key functions identified in this issue brief: pace-setting, driving ambi- tion, holding countries accountable, and sending implementation signals to reach the Paris Agreement's mitigation, adaptation, and financial goals. The GST's success will not only hinge on the fulfilment of these functions but also on how the international community will assess progress based on equity, and how the delicate balance negotiated in Katowice to address Parties' concerns will be maintained. This is why recommendations from independent organizations on how the GST can be made more robust, equitable, and effective are relevant and timely for consideration by the United Nations Framework Convention on Climate Change (UNFCCC).

\section{About This Issue Brief}

This issue brief reviews ways to make the GST most effective within the confines of the structure already negotiated. It builds on publications under the Independent Global Stocktake (iGST)-a collaborative effort by climate modelers, analysts, campaigners, and advocates that aims to support the GST process. It was prepared on the basis of a multiyear research effort by multiple organizations under the iGST's "Designing a Robust Stocktake" discussion series, which analyzes the GST from a variety of angles, such as mitigation, adaptation, finance, and equity. The publications in this series were produced through targeted interviews, discussion webinars, written feedback, and direct inputs.

\section{Process Elements of the GST}

\section{The GST is a clearly structured sequence to assess progress toward the Paris goals. Clarity on the} structure of the GST is crucial to provide the foundation necessary for the GST to directly address progress toward the long-term mitigation, adaptation, and financial goals in Article 2.1(a-c) of the PA and to hold countries accountable to their commitments. This issue brief suggests that the GST could be structured in the following way:

- Structure the technical assessment in three sets of discussions: the first set will be related to the thematic areas identified in the Katowice decision (mitigation, adaptation, and means of implementation and support); the second set of discussions will address loss and damage and response measures; and, in the third set, Parties will ultimately assess the overall 
progress against the overarching long-term temperature, adaptation, and alignment of financial goals of the PA. The co-facilitators of these discussions will need to maintain a delicate balance and holistic view throughout the process. This structure can also help frame the collection of outputs and could be replicated at the high-level segment.

- Provide a set of guiding questions for all three components that encourage Parties and key stakeholders to look backward (to assess progress made toward the global commitments ${ }^{1}$ ) and forward (to identify what action is needed and to signal plans and the intent to step up climate actions and support).

Clarity on timelines. Considering the overlap between different components of the GST, clearly delineating them is critical to ensuring an effective GST cycle that is well synchronized with other mechanisms within and outside the UNFCCC and optimizes the GST's pacesetting function:

- Set clear deadlines for the production and delivery of outputs of the GST and either strongly encourage or clearly allocate responsibility for the tasks, inputs, and outputs to be shared and coordinated among the various UNFCCC bodies.

- Ensure linkages between the GST and other processes, such as the transparency framework and the Intergovernmental Panel on Climate Change (IPCC) cycles, through the guaranteed active participation of constituted bodies and other organizations, so that the GST has the information it needs to undertake thorough assessments.

Robust sources of input. Robust, high-quality information will be critical for the credibility and legitimacy of the GST and will enable it to fulfil its transparency and accountability functions. This issue brief suggests that additional guidance be provided regarding the sources of information (including consistent formats), the types of information (both qualitative and quantitative) that the GST assesses, and the guiding questions mentioned above.

\section{Equitable and inclusive participation and engage-}

ment. The GST will not be able to act as a driver of ambition without equitable participation by all Parties and effective engagement with non-Party stakeholders and institutions outside the UNFCCC. Broad participation will elevate the GST's legitimacy and secure more international and domestic buy-in to the Paris goals. It will also encourage government accountability and advance the GST's objective of enhancing international cooperation. In addition, the following suggestions aim to better equip Parties with the information they need to engage equitably in the process toward shaping the outcome:

- Involve finance, planning, and line ministries in the GST, which may have more weight than environment ministries, to strengthen equitable participation and leverage sectoral and thematic expertise. This could be done through in-person and virtual technical dialogues.

- Identify and redress information gaps where possible by collecting information from a diversity of Parties and a variety of stakeholders, increasing the opportunity for broader Party and stakeholder input, and ensuring balance and equity in the sources of input.

- Encourage national, regional, and multi-stakeholder convenings, and GST-related dialogues outside the official GST events as a way to encourage transparency and secure thematic expertise necessary for adequate coverage of specific themes that are important to countries. This would allow for broader Party engagement.

- Set up a support process to help identify relevant non-Party stakeholders as participants in the GST and benefit from their thematic information and expertise. This can be driven in part by the HighLevel Climate Champions. ${ }^{2}$

- Hold regional convenings in collaboration with international institutions such as the World Bank, the International Monetary Fund (IMF), the Food and Agriculture Organization (FAO), the International Maritime Organization (IMO), the International Civil Aviation Organization (ICAO), and the World Health Organization (WHO) to ensure that GST-related questions link to other agendas (Northrop et al. 2018).

- Secure adequate budgeting and provision of predictable support to developing countries to facilitate their participation, including information gathering and analysis. 
Making the outputs politically impactful. The outputs of the GST must carry political weight to enhance the legitimacy of the process and fulfil its purpose:

- Deliver the outputs of the final component via highlevel events spread throughout the two weeks of the COP to ensure balanced consideration of each thematic area and the involvement of non-Party stakeholders.

- Secure high-level participation in the final component of the GST to ensure its outputs are taken up at the national level.

- Clarify the format for the outputs of the final component so that they reflect both technical discussions and political outcomes. This would include a CMA
(Conference of the Parties serving as the Meeting of the Parties to the PA) decision that fully endorses the GST's results.

Translating outputs into outcomes. The time between the third component of the GST and the submission of the next round of Nationally Determined Contributions (NDCs) should be leveraged to translate the outputs of the GST into the desired outcomes of enhanced climate actions and support and strengthened international cooperation:

- Build political momentum within the GST by making it more equitable and inclusive, as described above. Built-in political momentum from the GST process can be carried over into the national NDC revision and enhancement processes.

\section{OUTLINING THE SUGGESTIONS TO ADDRESS PROCESS GAPS AGAINST THE GST COMPONENTS}

\section{Setting clear deadlines for production and delivery of outputs}

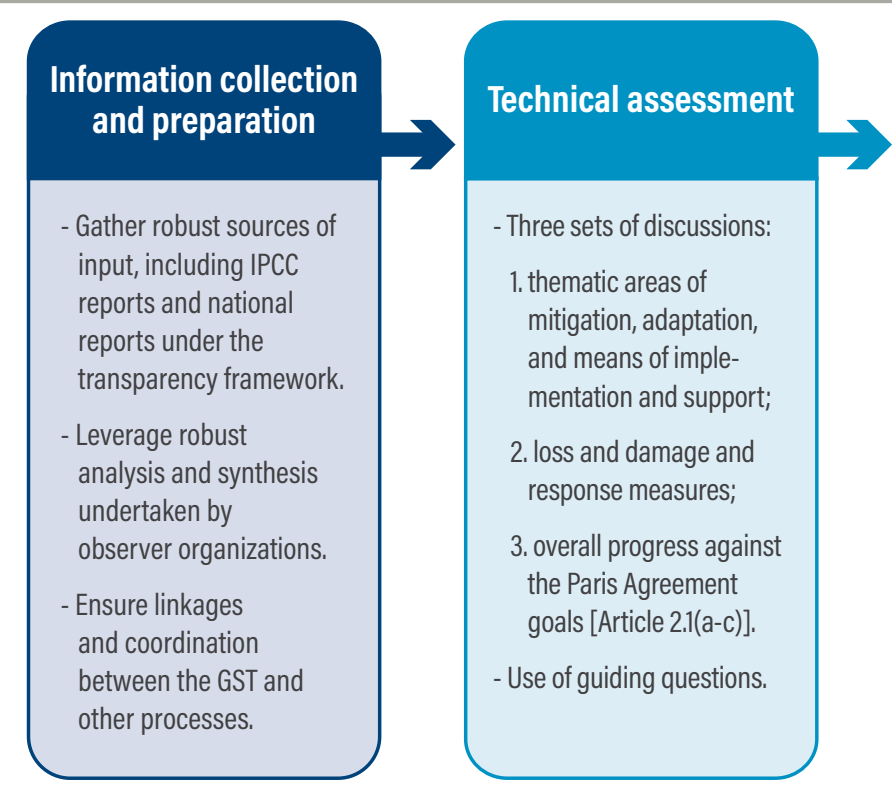

After the GST and before the next GST

- Build and/or maintain political momentum. - Leverage other multilateral, regional, sectoral, national fora, and multi-stakeholder dialogues outside the UNFCCC. 
- Leverage other technical and political processes at the national and international level to ensure that the GST becomes relevant in country contexts. This includes greater engagement with other international institutions such as the World Bank, IMF, FAO, WHO, ICAO, and IMO, to appraise the findings of the GST for action in different regions and sectors.

\section{Information Elements of the GST}

The availability of relevant input is crucial to the GST's ability to assess collective progress toward the long-term goals. There are still substantial information gaps related to the long-term goals and the three thematic areas of mitigation, adaptation, and means of implementation and support. Such information is relevant to all components of the GST. This issue brief provides suggestions on how progress toward the longterm goals can be assessed in depth within the bounds of the GST and examines the cross-cutting issues of indicator selection and equity (Holz et al. 2019). This brief also acknowledges that there are limitations to how much the GST can address information gaps, and that some will need to be covered from outside the bounds of the GST.

Addressing gaps and uncertainties related to the long-term mitigation goal. ${ }^{3}$ Most uncertainties relate to the diversity and divergence of recommendations on how to close the emissions gap to achieve the long-term goal of keeping the increase in global average temperature to well below $2^{\circ} \mathrm{C}$ above pre-industrial levels and how to fairly distribute efforts across sectors and countries over time. Based on the experience of other review processes within UNFCCC, we suggest the following ways in which the GST could effectively strengthen our knowledge of how to decarbonize the world by 2050 and reach net-zero $\mathrm{CO}_{2}$ emissions:

- Disaggregate the assessment of mitigation trends to the sectoral level.

- Provide space for sharing best practices and lessons learned and reflect this in the output.

- Highlight links to loss and damage and response measures.

- Identify, showcase, and assess non-Party stakeholder actions in addition to action contained in the NDCs.
Addressing information gaps related to the longterm adaptation goal. ${ }^{4}$ The long-term adaptation goal is qualitative, making it difficult to assess collective progress. There is no common understanding of what an "adequate adaptation response" is (Höhne et al. 2019) and no commonly agreed metrics to monitor adaptation efforts. Given these gaps, the GST can helpfully address adaptation by taking the following steps:

- Collect activity-focused information identifying both quantitative and qualitative data relevant to appraise collective efforts at the regional, sectoral, thematic, and systems levels.

- Adopt a methodology-focused approach that would review available methodological information to assess and aggregate adaptation data at the national and international levels, with a view to better define an "adequate" adaptation response.

Addressing information gaps related to the longterm financial goal. 5 There is a risk that collective progress toward the consistency of financial flows with the Paris goals may not be sufficiently integrated into the GST, compared to the treatment of means of implementation and support. In addition, information on capacity building, technology, and on consistency of financial flows is scattered. This issue brief suggests the following options for the GST:

- Build consensus on what constitutes Paris-compatible financial flows.

- Assess the balance between financial and other resources (capacity building, technology) needed, provided, and mobilized for adaptation and mitigation.

- Assess how much climate ambition can be enhanced through alignment and mobilization of finance.

Addressing crucial intersections between the choice of indicators and equity. Assessments performed under the GST will need to benchmark data and information against some indicators in order to evaluate global efforts. While it is unlikely that Parties will be able to agree on such indicators due to the politics of what they report, independent analysis of the GST assessments using more granular indicators could be leveraged. Independent analysis would likely be necessary if the assessments are to reflect equity and ensure the GST's legiti- 
macy in the multilateral process. Challenges arise because of the collective nature mandated for the GST assessment, which obscures comparisons among countries. Hence, this issue brief suggests the following:

- A process for selecting and using a range of indicators to facilitate and support the thematic assessment of collective efforts.

- Building equity into the indicators, for example, in relation to countries' historical responsibility, and capacity to implement climate solutions such that the limitation of addressing collective progress can be overcome without exceeding the GST's mandate.

The challenges, gaps, and uncertainties identified above are cross-cutting and will surface in all three components of the GST. There is scope to address them within the GST itself. Mechanisms can be established that allow for information gaps to be identified and addressed, and provide equitable opportunities for Parties and for non-Party stakeholders to contribute input. The various components of the GST at UNFCCC sessions and beyond, the selection of indicators, and the format and structuring of discussions and outputs will influence the political outcome and overall impact. While the recommendations in this issue brief acknowledge the challenges and limitations of the GST, they also provide a pathway to a more comprehensive, transparent, and equitable process that will hopefully produce an accurate, thorough, and politically relevant assessment of the state of global climate action.

\section{Independent organizations such as think tanks} and NGOs may have to play a critical role in reducing some of the gaps. There may be gaps that the GST will not have the mandate or the capacity to address, and independent contributions will help make the process more equitable, transparent, and effective, both through the provision, analysis, and dissemination of information and their participation in the GST.

Whether governments will be able to go beyond their comfort zone and express ambitious aspirations based on tough science-based decisions remains to be seen. For the PA to make the required difference at the scale and pace that is needed-especially in terms of enhancing NDCs and climate finance-the GST will need to mobilize compelling data, create international and domestic pressure, and generate political momentum in order to achieve its desired outcomes.

\section{INTRODUCTION}

The GST is a process established under Article 14 of the PA to periodically take stock of collective progress toward achieving the PA's long-term mitigation, adaptation, and financial goals. The first cycle of the GST is to take place in 2022-23 and every five years thereafter. It must be conducted in a comprehensive and facilitative manner, considering mitigation, adaptation, and the means of implementation and support, and in the light of equity and the best available science.

\section{Negotiation Context}

The GST is a key component of the Paris architecture in support of the ambition cycle. The PA stipulates that "the outcome of the GST shall inform Parties [to the Paris Agreement] in updating and enhancing, in a nationally determined manner, their action and support in accordance with the relevant provisions of [the] Agreement, as well as enhancing international cooperation for climate action" (UNFCCC 2015). This means that following the completion of a GST, Parties are expected to prepare more ambitious NDCs informed by the GST's results, ${ }^{6}$ taking into consideration common but differentiated responsibilities and respective capabilities and national circumstances, and when possible or necessary, through international cooperation. The GST must be operationalized effectively given that most NDCs are currently not on track to meet the PA's climate goals.

At COP24 in Katowice in 2018, Parties negotiated the core elements of the modalities and procedures of the GST and identified relevant sources of information (inputs). ${ }^{7}$ The GST will be conducted in three components over 18 to 24 months: collection of information and preparation, a technical assessment, and considerations of outputs (Figure 1). The Katowice decision established that the GST must organize its work in line with the assessment of the long-term Paris goals for mitigation, adaptation, and alignment of financial flows and means of implementation and support (referred to in this issue brief as "thematic areas"). The Katowice decision also says that the GST process may take into account efforts to address social and economic consequences and impacts of response measures (i.e., policies to address climate change), as well as efforts to avert, minimize, and address loss and damage caused by the adverse effects of climate change. ${ }^{8}$ 


\section{UNPACKING THE MANDATES OF THE GLOBAL STOCKTAKE}

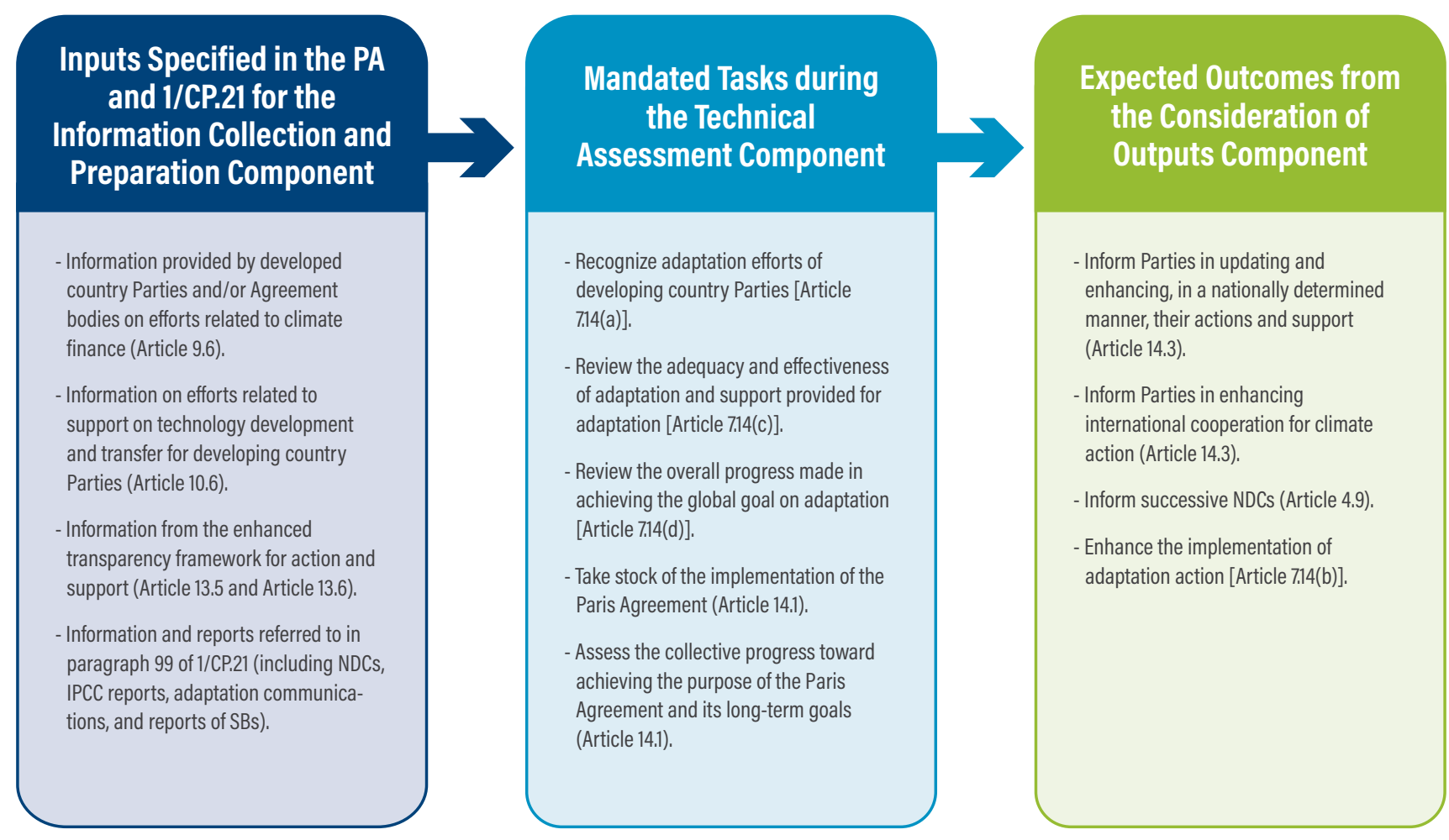

Source: Based on data from Northrop et al. (2018).

The Katowice decision does not offer complete guidance on how to organize the substantive GST discussions, or the timeline, sources of inputs, participation and engagement, and outputs. These process issues still need to be fleshed out by the co-facilitators of the technical dialogues, as well as the chairs of the Subsidiary Body for Scientific and Technological Advice (SBSTA) and Subsidiary Body for Implementation (SBI). If the GST is to fulfil its purpose of informing more ambitious NDCs and catalyzing the necessary level of enhanced international climate cooperation, it will also need to address information gaps and uncertainties related to the information and data available to inform the assessment of the longterm goals.

\section{About This Issue Brief}

This issue brief assesses how the GST can be most effective in catalyzing enhanced action and support to meet the PA's goals. It first describes what we know of the main components of the GST, and elements related to the scope, timeline, sources of input, participation, organizational issues, and output, based on the Katowice decision. For each element, this issue brief highlights how it connects with the identified functions of the GST, identifies gaps left by the Katowice decision, and proposes ways to fill these gaps and make the GST more effective. This issue brief identifies two types of gaps: process gaps, intrinsic to the mechanisms of the GST, and information gaps and uncertainties related to the sources of input that will inform the three thematic areas. ${ }^{9}$

This issue brief is part of a multipart, multiyear research effort within the Independent Global Stocktake (iGST). The iGST is a collaborative effort by climate modelers, 
analysts, campaigners, and advocates that aims to support the GST process by increasing its accuracy, transparency, accountability, and relevance.

More specifically, this issue brief builds on the publications under the iGST's "Designing a Robust Stocktake" discussion series, which analyzes the GST from a variety of angles, including the following:

- "Guiding Questions for the Global Stocktake under the Paris Agreement: What We Know and What We Don't" by Höhne et al. (2019): A response to the Katowice decision's request ${ }^{10}$ to develop guiding questions for the GST.

- "Success Factors for the Global Stocktake under the Paris Agreement” by Obergassel et al. (2019): An analysis showing how the GST can maximize its potential impact.

- "Design Options for the Global Stocktake" by Beuermann et al. (2020): A review of the lessons learned from other collaborative processes.

- "Understanding Adaptation in the Global Stocktake" by Christiansen et al. (2020), "Mitigation Information and the Independent Global Stocktake" by Clark and Hultman (2020), and "Understanding Finance in the Global Stocktake" by Watson and Roberts (2020): Analyses of how existing data sources can inform the GST and contribute to achieving the PA's long-term goals on adaptation, mitigation, and finance, respectively, considering the implications and gaps in guidance for these discussions in the GST.

- "Equity in the Global Stocktake and the Independent Global Stocktake” by Holz et al. (2019): A mapping of equity as a cross-cutting consideration in order to fulfil the PA's mandate to perform the GST "in light of equity."

Multiple organizations ${ }^{11}$ have combined their expertise to produce the papers in this discussion series through targeted interviews, discussion webinars, written feedback, and direct inputs.

It would be useful if coordinating mechanisms were established as early as now to ensure linkages between the UNFCCC and independent organizations already thinking about how to design a robust GST, to ensure their work and suggestions are fed to the UNFCCC and that work done by those organizations responds to the UNFCCC's needs.

\section{A Vision of Success for the GST}

A successful GST is one that will provide Parties with a thorough assessment of the state of collective climate action, leading countries to improve their national climate efforts to keep temperature increase below $1.5^{\circ} \mathrm{C}$, enhance our ability to adapt, and scale up support at the scale and speed necessary to sustainably decarbonize our economies and make our societies more resilient. For this to materialize, two things need to happen. First, the processes underlying the operationalization of GST will need to be comprehensive, transparent, and equitable so as to generate the accountability and trust that will encourage countries to strengthen their climate action and support. Second, a thoroughly participatory process, engaging stakeholders beyond Parties, will help build up the political momentum within the GST that can trigger nationally enhanced ambition as well as increase climate action from non-state actors. A successful GST that facilitates transformational change is thus one that is conceived as a process, rather than an event.

If the GST is to succeed in ultimately spurring enhanced climate ambition, it is crucial that the two-year time period between the end of the GST process and the COP, at which enhanced NDCs are expected to be announced, is used astutely. The political momentum generated by building up the buy-in and engagement from all stakeholders during the GST process should be carried over into participatory national NDC revision processes, allowing the GST to become the feedback mechanism that can ratchet up action and help align short-term NDCs with the long-term goals of the PA (Obergassel et al. 2019). Parties will need to harness the lessons from other established processes, ${ }^{12}$ reflect on ways to address the limitations of the first GST cycle, and improve the process for the next round.

In order to demonstrate how the GST can be made most effective within its bounds, it is crucial to clearly acknowledge the challenges and limitations inherent in the GST. Firstly, because of its mandate to assess collective progress toward the longterm goals, without singling out countries, it will be difficult for the GST to directly point out country-specific lack of ambition or highlight country-specific opportunities to do more. Given the bottom-up nature of the regime, the GST may not be as explicit about how to equitably 
share the efforts between countries toward achieving the climate goals. Some of those challenges can be partly overcome if the GST is able to generate politically relevant outputs (see Section 4.5). In order to prevent inherent limitations from obstructing the enhancement of climate ambition, independent observers' analysis and inputs to the GST can be leveraged to ensure that the global outputs of the GST are made nationally relevant.

\section{Independent observers to the GST can play an important role in overcoming information gaps} relevant to the GST. The GST can only provide an assessment of collective climate action when the input is available for it to assess. To some extent, the GST can provide policy-relevant assessments that can steer greater climate action by drawing conclusions as much from the information considered as from the information gaps. But concretely, the GST's information gaps and uncertainties may be filled by other organizations as they can produce the relevant data and contribute to building common understanding on several substantive issues.

\section{WHAT HAS ALREADY BEEN DECIDED ABOUT THE GST?}

At COP24, Parties agreed to greater specificity than was provided by provisions in the PA itself about how the GST will be conducted. The governance of the GST has three layers: CMA will conduct the high-level discussion, SBI and SBSTA will assist the political discussion jointly, and Parties will engage in technical dialogues. ${ }^{13}$

\section{Length, Timeline, and Components}

The GST process will involve three components (Figure 2): the first GST will unfold over 18 months, from June 2022 to November $2023 .{ }^{14}$ The cycle will repeat every five years. ${ }^{15}$

\section{Component 1: Information collection and prepa-} ration. The first component gathers, compiles, and synthesizes information in preparation for the technical assessment component. It aims to provide the GST process with the information required to deliver the expected outcomes.

According to the Katowice decision, information sources will at a minimum ${ }^{16}$ include communications from Parties, including the latest NDCs and individual countries' progress reports submitted to fulfil the transparency requirements under the UNFCCC, the latest Intergovernmental Panel on Climate Change (IPCC) reports, reports from the Subsidiary Bodies (SBs) and from relevant constituted bodies, ${ }^{17}$ the Synthesis Reports (SYRs) that are to be produced by the UNFCCC secretariat as output for this component, relevant reports from international organizations and regional groups, and voluntary submissions from Parties. Submissions from non-Party stakeholders and observer organizations will also be considered. ${ }^{18}$ The GST will consider information at the collective (global) level on several themes related to the long-term goals. ${ }^{19}$

Information collection is to begin one negotiating ${ }^{20}$ session before the start of the technical assessment and terminate no later than six months before the final stage involving the "consideration of outputs." Inputs should be submitted at least three months before their consideration in the technical assessment. ${ }^{21}$

Component 1 outputs will be produced by the two co-facilitators with the assistance of the UNFCCC secretariat. ${ }^{22}$ They will include four SYRs for the technical assessment on synthesizing information collected on greenhouse gas (GHG) emissions by sources and removals by sinks, and mitigation efforts undertaken by Parties; overall effect of NDCs and overall implementation progress made by Parties; the state of adaptation efforts, support, experience, and priorities; and financial flows, means of implementation and support, and the mobilization and provision of support. ${ }^{23}$

Component 2: Technical assessment. The second component involves a collective review of information, assessment of collective progress toward achievement of the long-term goals, and identification of opportunities for enhanced action and support. At the heart of this component is the establishment of a facilitated, open, inclusive, and transparent technical dialogue structured around in-session workshops and roundtables. It should give balanced allocation of time to the three thematic areas. This technical dialogue will take place only when the SBs are in session. ${ }^{24}$ The technical assessment can start either a year or a year and a half ${ }^{25}$ ahead of the COP, during which time the consideration of outputs will take place. ${ }^{26}$

The outputs of the technical dialogue consist of summary reports produced by the co-facilitators with assistance from the UNFCCC secretariat for the three 


\section{UNPACKING THE COMPONENTS OF THE GST}

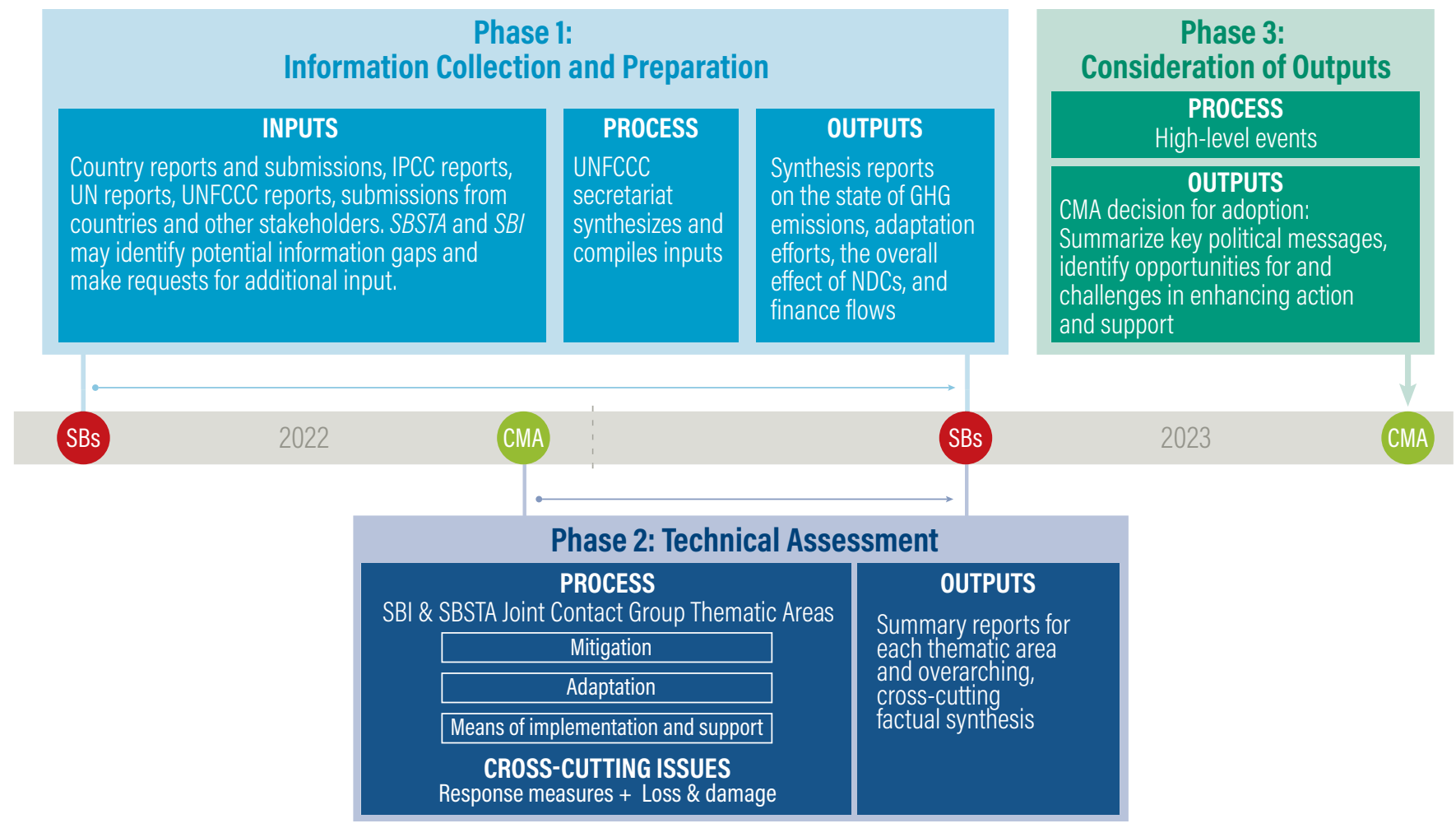

Source: Cogswell and Dagnet (2019).

thematic areas, as well as an overarching, cross-cutting factual SYR. ${ }^{27}$ Those outputs feed directly into the subsequent component.

Component 3: Consideration of outputs. The third component is the most consequential. Its results will determine the type and strength of the signals and guidance ${ }^{28}$ that will inform the revision and enhancement of climate action, support, and international cooperation. It involves high-level events ${ }^{29}$ that will consider the findings of the technical assessment around the three thematic areas and their implications for achieving the outcomes of the GST. The outputs of this component will identify opportunities for and challenges to enhancing action and support for collective progress, as well as possible measures and good practices in international cooperation. They will also summarize key political messages and recommendations for strengthening action and support.
Most importantly, this third component can conclude with a CMA decision by the Parties, and/or a declaration, that references its outputs. ${ }^{30}$

\section{CORE FUNCTIONS OF AN EFFECTIVE GST}

We know that to achieve the Paris goals, transformative global socioeconomic change is required. The GST forms part of the ambition mechanism under the PA to ensure that Parties take greater action over time. For the GST to support transformational change and fulfil its mandate within the Paris architecture, Jeffery et al. (2019) and Obergassel et al. (2019) identified core functions that an effective (ideal) GST should operationalize, and which this section builds on. 


\section{What Is an Effective GST?}

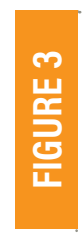

\section{FOUR FUNCTIONS OF AN EFFECTIVE GST}

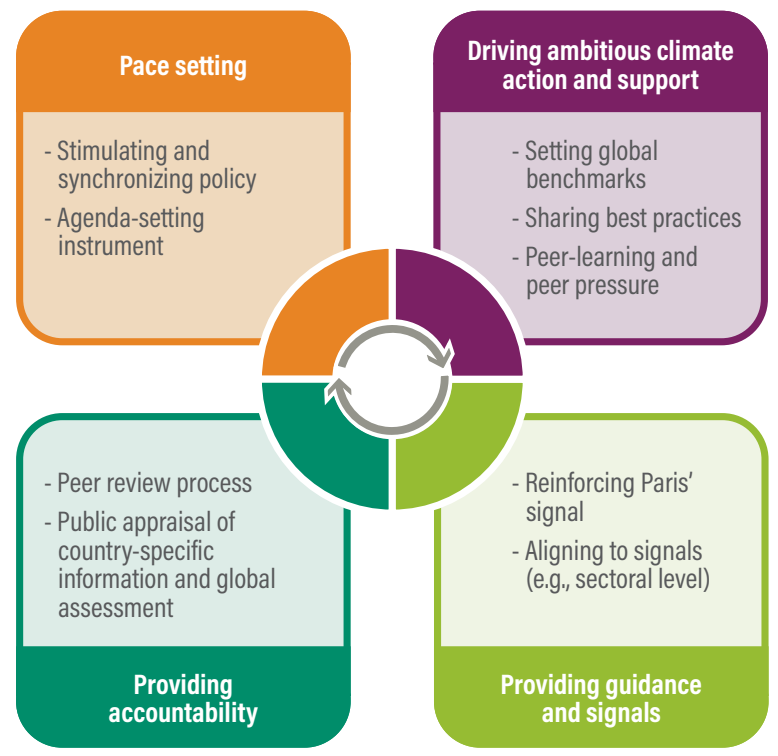

Source: Based on content from Jeffery et al. (2019).

\section{Setting the Pace}

An effective GST, through its five-year ambition cycle, would trigger a pace-setting process encouraging policymakers to better synchronize their national planning and implementation processes through regular successive rounds of NDCs. It would also encourage countries to better align their short-term NDCs with the three long-term goals of the PA on mitigation, adaptation, and finance. The UNFCCC and the NDC processes have proved useful to set the international agenda and mainstream climate in national planning processes. If well operationalized, the ambition cycle established by the PA, and formalized in the GST, can institutionalize this catalytic function (Obergassel et al. 2019).

The GST's broad mandate can also help identify synergies with climate-relevant processes outside of the UNFCCC, such as the 2030 Agenda for Sustainable Development, by promoting interaction with other international institutions outside the UNFCCC. As a result, the GST's five-year cycle can also set the pace for any evaluation of consid- erations in institutions in the fields of trade, investment law, food and agriculture, development cooperation and financing, financial stability, and the 2030 Agenda for Sustainable Development (Northrop et al. 2018).

\section{Providing Accountability}

Transparent and inclusive processes that embrace Party and non-Party stakeholder participation will foster accountability and credibility to effectively drive transformational change. An effective GST process would build political momentum and invite public and media scrutiny by generating compelling information with the appropriate amount of granularity, without exceeding its mandate of assessing collective progress. For example, instead of providing one broad assessment of collective progress, the GST could disaggregate the evaluation into groups of countries, according to historical responsibility and capability. This would draw attention to who is doing what, without pointing fingers.

\section{Providing Guidance and Sending Signals}

An effective GST would signal to all stakeholders on countries' determination to pursue a course of action toward global decarbonization at the pace and scale required..$^{31}$ The PA provides general guidance on the direction of travel toward net-zero GHG emissions and climate-resilient economies and societies, ${ }^{32}$ together with a manual on how to do this transparently and in a fair way ${ }^{33}$ However, the guidance often lacks specificity on implementation. The GST can provide clearer signals and more detailed supporting guidance emerging from a thorough assessment of collective progress toward decarbonization goals, highlighting the adequacy-or otherwise-of current action and support, linking current levels of mitigation with correspondingly higher or lower levels of adaptation, promoting knowledge on policy design and implementation and support required, and promoting the sharing of good practices, challenges, successes, and lessons learned.

\section{Driving More Ambitious Climate Action and Support}

Article 14 of the PA and the Katowice decision both establish that the successive NDCs are informed by the outcome of the GST. ${ }^{34}$ This makes the GST a critical mechanism for the ambition cycle. Effectively operationalized as the periodic feedback mechanism, the GST could affect national levels of ambition in every successive round of NDCs. Success will depend on the GST's ability 
to leverage and generate scientific, economic, technical, and policy-related knowledge, promote learning and understanding of solutions to the climate problem, and share best practices and lessons learned that could serve as reference points and benchmarks for countries, and for non-state and subnational actors (Obergassel et al. 2019). Political momentum will need to be built into the GST process through inclusive and transparent participation and persist after the GST in national NDC revision processes.

\section{PROCESS GAPS IN THE GST AND SUGGESTIONS FOR IMPROVEMENT}

This chapter highlights how the following elements of the GST process could be refined:

- Organizing the work of the GST

- Timeline

- Inputs

- Participation and engagement

- Outputs

We identify the main gaps and challenges inherent in these core process elements and suggest ways (highlighted in boxes) to successfully operationalize an effective GST.

\section{Organizing the Work of the GST}

According to the PA, the purpose of the GST is to "assess collective progress toward [the Agreement's] long-term goals, [...] considering mitigation, adaptation and the means of implementation and support.” This guidance leaves space for much interpretation, which was unpacked in Northrop et al. (2018). A clear sequence would be required to break up the GST assessment into manageable pieces, mindful of the mandated scope.

The question is whether to organize the work of the GST around the three thematic areas or around the long-term goals of the PA and how to sequence the second component of the GST without creating siloed considerations under the GST. This becomes even more relevant when contemplating a broader scope from the Katowice decision, calling for Parties to also consider the implications of handling loss and damage and response measures. ${ }^{35}$
Equity should not only be appropriately considered within each thematic area-each sequential discussion should also be given equitable and balanced treatment in the process.

This structure would allow for more comprehensive consideration of each long-term goal and would, for instance, signal the importance of the means of implementation and support in fulfilling each long-term goal. It would also highlight the implications of delaying achievement of mitigation or adaptation goals, facilitate understanding of balanced allocation of efforts between adaptation and mitigation, and of the implications of losses and damages.

An important tool to frame the technical and high-level discussions and collection of inputs, as well as provide the necessary signals to drive ambition, will be the use of guiding questions analogous to those used to guide the Talanoa Dialogue in 2018-the COP's first attempt to convene a dialogue among Parties to take stock of collec-

\section{SUGGESTION FOR ORGANIZING THE SCOPE OF WORK OF THE GST}

- Organize the work of the GST during the technical assessment sequentially, with the thematic areas being the entry point and ultimately making the assessment against the three long-term goals under Aricle 2.1 (a-c) of the PA. This would ensure that the thematic areas are not understood narrowly.

- Consider the implications related to mitigation, adaptation, means of implementation and support, loss and damage, and response measures as per Figure 4.

- Designate two co-facilitators for each area of discussion: one from a developed country and the other from a developing one.

- Produce a summary of the discussions in each sequential discussion to ensure transparency and effectiveness. The co-facilitators, together with the Parties, can decide to what extent these summaries will be aggregated.

- Prevent the individual discussions (thematic areas, related to the long-term goals, or on loss and damage or on response measures) from happening simultaneously in order to allow cross-workstream participation and cross-pollination. 


\section{SEQUENCING THE WORK OF THE GST DURING THE TECHNICAL ASSESSMENT}
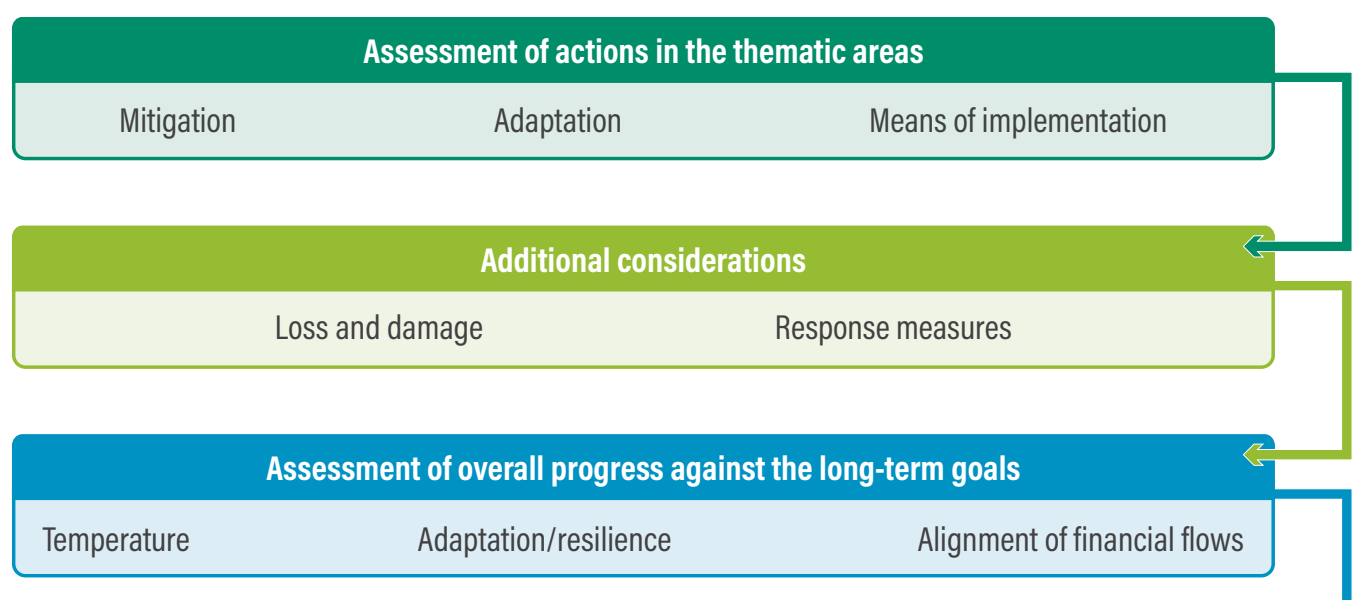

Summary of discussions

Summary of overall outcomes for input to the consideration of outputs component

Source: Authors.

tive efforts toward the long-term goals of the PA. Those questions are: Where are we? Where do we want to go? and How do we get there? They can provide a strong basis for the GST, but Parties recognized in Katowice that it will be necessary to generate more granular information triggered by more specific questions; for example, relating to sectoral action. Such questions could also generate input and strengthen participation from stakeholders outside the usual environment and climate spheres. The SB chairs will develop a set of guiding questions for the GST. ${ }^{36} \mathrm{We}$ present a possible set of questions in Appendix B.

\section{The Timeline}

The Katowice decision set out a three-component process for the GST, but the components overlap and coordination between them is unclear. While this ambiguity can be used to provide flexibility on how to run the process, clarity about timing would be crucial to ensure the GST's pace-setting function in relation to other mechanisms inside and outside of the UNFCCC. This section recognizes two main challenges-coordinating the components of the GST and synchronizing with other processes (especially transparency and IPCC cycles). ${ }^{37}$
Ensuring that the GST has the information it needs to undertake thorough assessments is partly dependent on ensuring timely linkages between the GST and the publication of national reports and communications from Parties under the PA and the UNFCCC. These include the biennial transparency reports (BTR) ${ }^{38}$ and National Inventory Reports (NIR), but also the outcome of the second periodic review. The new rules for more robust BTRs and NIRs begin in December 2024, a year after the completion of the first GST. This means that we can expect the first GST to be based on the less robust and limited number of reports generated under the UNFCCC. ${ }^{39}$ For future GSTs, two BTRs per cycle would ideally be available if all countries submit their reports on time. Many lessons can also be learned by including other communications with less defined cycles, such as National Adaptation Plans (NAPs), when they are available.

The IPCC reports are also key sources of scientific input for the GST process. In the case of the first GST, Parties agreed to make the IPCC's Sixth Assessment Report (AR6) available before the end of a typical IPCC assessment cycle, which usually lasts longer than five years. 
There may be considerable overlap between the information collection and preparation component and the start of the technical assessment. While technically there is a cutoff date for information collected ("at least three months before their consideration in the technical assessment"), ${ }^{40}$ the overlap allows for the GST to continue collecting information even after the cutoff. However, the lack of clarity regarding sequencing will impact the quality of the outputs from the beginning because it is unclear how the UNFCCC's secretariat can produce the SYRs that incorporate all the information collected in so little time, or how the secretariat can secure a robust and comprehensive compilation if the SYRs are prepared before all the information is collected. The volume of information that will likely be collected will present quite a challenge for the co-facilitators and the secretariat.

\section{Sources of Input}

The diversity of input documents will pose challenges. Lack of consistency will make data comparisons difficult, and sources of inputs could contain biases or lack transparency. These challenges will manifest during all three components of the GST and assume increasing importance in the technical assessment-that will assess not only the information collected but also the implications of the knowledge gaps-and in the consideration of outputs, which must translate the assessment of information and gaps into high-level political recommendations that will prompt enhanced climate action, support, and cooperation.

SBSTA should provide additional guidance on the types and sources of input necessary to ensure that the GST assesses information across its full scope and, therefore, benefits from different perspectives that multiple sources can bring, in spite of potential data gaps.

While the Katowice decision makes explicit references to some sources of inputs for the GST, it does not make clear how long-term strategies, which countries are encouraged to produce, can be taken into account. Such efforts by countries should be leveraged and used to also gauge the progress made toward the long-term goals, as well as identify what is needed in terms of longer-term pathways.

\section{SUGGESTIONS FOR ADVANCING THE TIMELINE}

\section{SYNCHRONIZING THE COMPONENTS}

- Preparation of the four SYR: Parties could agree that the UNFCCC secretariat should begin preparation of the four SYRS immediately after the cutoff date and ensure that these are ready in time for the technical assessment. Inputs arriving later can be aggregated into addenda of the main SYRs.

- Role of constituted bodies: The various constituted bodies and forums serving under the PA and the UNFCCC could sift the information submitted by the Parties, identify information relevant to their areas of expertise, and include it in their SYRS, which they are invited to produce. ${ }^{\text {a }}$

- Remaining information: This could be summarized by the secretariat. The High-Level Climate Champions could be mandated to review and summarize input from stakeholders (Northrop et al. 2018) into an SYR that would aggregate stakeholder actions. Or the secretariat could include remaining information in the main SYRs as a distinct section (e.g., analysis by non-Party stakeholders about Parties' efforts and progress toward the PA goals).

\section{LINKAGES BETWEEN THE GST AND OTHER PROCESSES} (TRANSPARENCY AND IPCC CYCLES)

- Centrality of the transparency reports: Parties should appreciate the centrality of the information generated under the transparency framework as input to the GST and strive to meet the frequency and quality requirements under both the UNFCCC and the PA's Enhanced Transparency Framework (ETF). Ahead of the first component of the GST, the UNFCCC secretariat could issue a notice highlighting the centrality of transparency reports for the proper undertaking of the GST.

- Inputs from the IPCC: If a full IPCC AR is not available, the GST can be informed by IPCC Special Reports that follow shorter timelines, and by the reports produced by the IPCC Working Groups. ${ }^{b}$ An outcome of a GST could be a request to the IPCC to produce a report on a specific theme or gap to inform the next GST and enhance future opportunities for action and support.

a Paragraph 24 of 19/CMA.1.

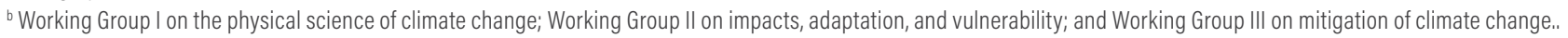




\section{SUGGESTIONS TO HELP MAXIMIZE THE TRANSPARENCY, ACCURACY, COMPLETENESS, CONSISTENCY, AND COMPARABILITY OF INPUTS}

\author{
- Parties could agree to a five-year common timeframe (i.e., \\ end dates) for targets in their NDCs. This would align Parties' \\ schedules and greatly enhance the GST's ability to compare and \\ assess collective climate action and support. \\ - The UNFCCC secretariat could produce an SYR collating \\ the aggregate results, efforts, and progress emerging \\ from the BTRs and their review. SBSTA, in collaboration with \\ the Adaptation Committee, could produce technical guidance \\ specific to adaptation on metrics that could be used to facilitate \\ the assessment and measure progress toward the adaptation \\ goal-specifying what qualitative information through countries' \\ self-assessments, or quantitative information or both would
}

\author{
serve as relevant inputs. Such technical guidance could be \\ informed by the outcome of convenings, analysis, and sugges- \\ tions emerging from independent observer organizations. \\ - To assess the consistency of financial flows with Paris \\ goals, input must come from relevant actors outside the \\ UNFCCC and governments because data available through \\ UNFCCC processes will be limited to a subsection of all financial \\ flows from a subsection of all Parties. Approaches and meth- \\ odologies to aggregate this input will have to be developed by \\ SBSTA in collaboration with those actors and with the Standing \\ Committee on Finance.
}

\section{Participation and Engagement in the GST}

To be effective, the GST needs a process for equitable participation by all Parties in all its components, a process for non-Party stakeholders to engage meaningfully in the GST, and ways for the GST itself to engage with international institutions beyond the UNFCCC. By "equitable participation" we mean not only fair representation with geographic diversity and gender balance but also involvement that is not limited to attendance at GST events. Equity demands active engagement in the submission, collection, and preparation of information during the first component, effective engagement in the discussions under the technical dialogue, and discussions on the implications of the findings of the technical assessment. Broad and equitable participation is crucial if the GST is to perform its function of driving climate action, support, and international cooperation.

Ensuring an equitable process for Party participation is necessary to make the GST legitimate in the eyes of all Parties, which can improve their will and capacity to work together toward a common goal, leading to enhanced ambition from all (Al-Zahrani et al. 2019). The Katowice decision establishes the GST as a Party-driven process and directs that the technical dialogue be facilitated by two co-facilitators, one from a developed country and the other from a developing one. ${ }^{41}$ The decision suggests the provision of "adequate" funding for the participation of developing country Parties in all activities under the
GST, ${ }^{42}$ but invites developed country Parties to mobilize support for capacity building so that developing countries can effectively participate, ${ }^{43}$ which implies voluntary provision of such support. Processes need to be put in place to secure the participation of all Parties.

Wider stakeholder engagement will enable the GST to gather benchmarking and advocacy-related information. Stakeholders can demonstrate the transitions underway, and openly make the case throughout the GST for increasing ambition, thereby building political momentum and motivating more climate action and support from governments (Northrop et al. 2018). Expert participation in all components of the GST will also enhance the legitimacy of the GST outputs in the eyes of the public and media, as they would safeguard the technicality and scientific robustness of the assessment over politically negotiated outputs. The Katowice decision clarifies that non-Party stakeholders can provide written input during the first component of the GST process, ${ }^{44}$ but does not define a role for them in the technical dialogue and consideration of output components. Once this role is defined, it seems likely that developed country stakeholders would find the resources required to participate, but this may not be the case for developing country non-Party stakeholders. Mechanisms must be articulated to engage non-Party stakeholders in all three components. 


\section{SUGGESTIONS TO ENSURE BROAD AND EQUITABLE PARTICIPATION AND ENGAGEMENT IN THE GST}

- Engagement of line and planning ministries in various dialogues: Participation of non-environment ministries would secure the thematic expertise required both to assess the inputs and to discuss the implications of the findings of the technical dialogue. ${ }^{\mathrm{a}}$ Involving line and planning ministries can enhance developing countries' ability to engage effectively in the GST because environment ministries are sometimes less influential than other ministries.

- Collection of inputs: The mechanisms in the Katowice decision governing inputs could be refined. If information collected by the cutoff date is not reflective of balance and equity, additional information would need to be gathered from a diversity of Parties and a variety of stakeholders. Input collected after the official cutoff date would need enough time for summarizing into a format suitable for the technical dialogue, and be guided by equitable considerations. Collection of additional information should not be used to delay the start of the GST. Mechanisms to identify and redress gaps would ensure that inputs are not heavily dominated by developed country Parties.

- National, regional, and thematic dialogues: The UNFCCC could encourage countries and stakeholders to convene regional (e.g., through the regional climate weeks), national, or thematic GST-related virtual or in-person dialogues outside of UNFCCC intersessional sessions, during all components of the GST. Output from all components of the GST would need to be made publicly available, strengthening equitable Party participation and stakeholder engagement, and ensuring adequate coverage of specific themes that are important to countries. IPCC lead authors could participate, especially in the thematic convenings. Countries could report back on events through the co-facilitators, and stakeholders through the High-Level Climate Champions. Such convenings would increase possibilities for Parties to engage.
- UNFCCC support for broad stakeholder participation:

Parties and the secretariat could be asked to clarify how to leverage contributions from stakeholders beyond Parties in all components (including through SYRs).

The UNFCCC could set up a portal where stakeholders could register to officially become part of the GST process. Stakeholders could then access all the input online; review, comment on, and complement the input (Obergassel et al. 2019); and take part in the online technical dialogues. A portal would allow stakeholder participation beyond the nine constituencies ${ }^{b}$ currently under the UNFCCC that are generally represented during the COPs, to ensure geographical diversity and thematic expertise.

- Engagement and coordination with international institutions beyond the UNFCCC: During each component, the GST process could convene institutions such as the World Bank, IMF, the International Renewable Energy Agency (IRENA), FAO, WHO, ICAO, and IMO, among others, to consider progress on climate action and opportunities to strengthen that action. This will be particularly important for sectoral technical discussions. Convenings could also be held in regional contexts (e.g., through the regional climate weeks), to consider these questions and bring together policymakers, stakeholders, and others to address climate ambition and effective implementation. These convenings could engage international institutions in the process of gathering information, participation in the technical assessment, and in the high-level dialogue toward making the outputs politically impactful. The establishment of informal groups by the UNFCCC secretariat to make this happen could be helpful.

- Adequate budgeting by and/or provision of predictable support to developing countries for information gathering and analysis to facilitate their participation. Such activities need to be prioritized since they underpin both the quality of inputs provided and strengthen the ability of developing countries to engage as constructively and strategically as possible.

\footnotetext{
${ }^{a}$ For example, the high-level event to discuss the implications of the technical dialogue SYR on finance flows and means of implementation and support could see the participation of finance ministries.

${ }^{b}$ The nine constituencies to the UNFCCC are Business and Industry NGOs (BINGO), Environmental NGOS (ENGO), farmers, Indigenous Peoples Organizations (IP0), Local Governments and Municipal Authorities (LGMA), Research and Independent NGOS (RINGO), Trade union NGOs (TUNGO), Women and Gender, and Youth NGOs (YOUNGO).
} 


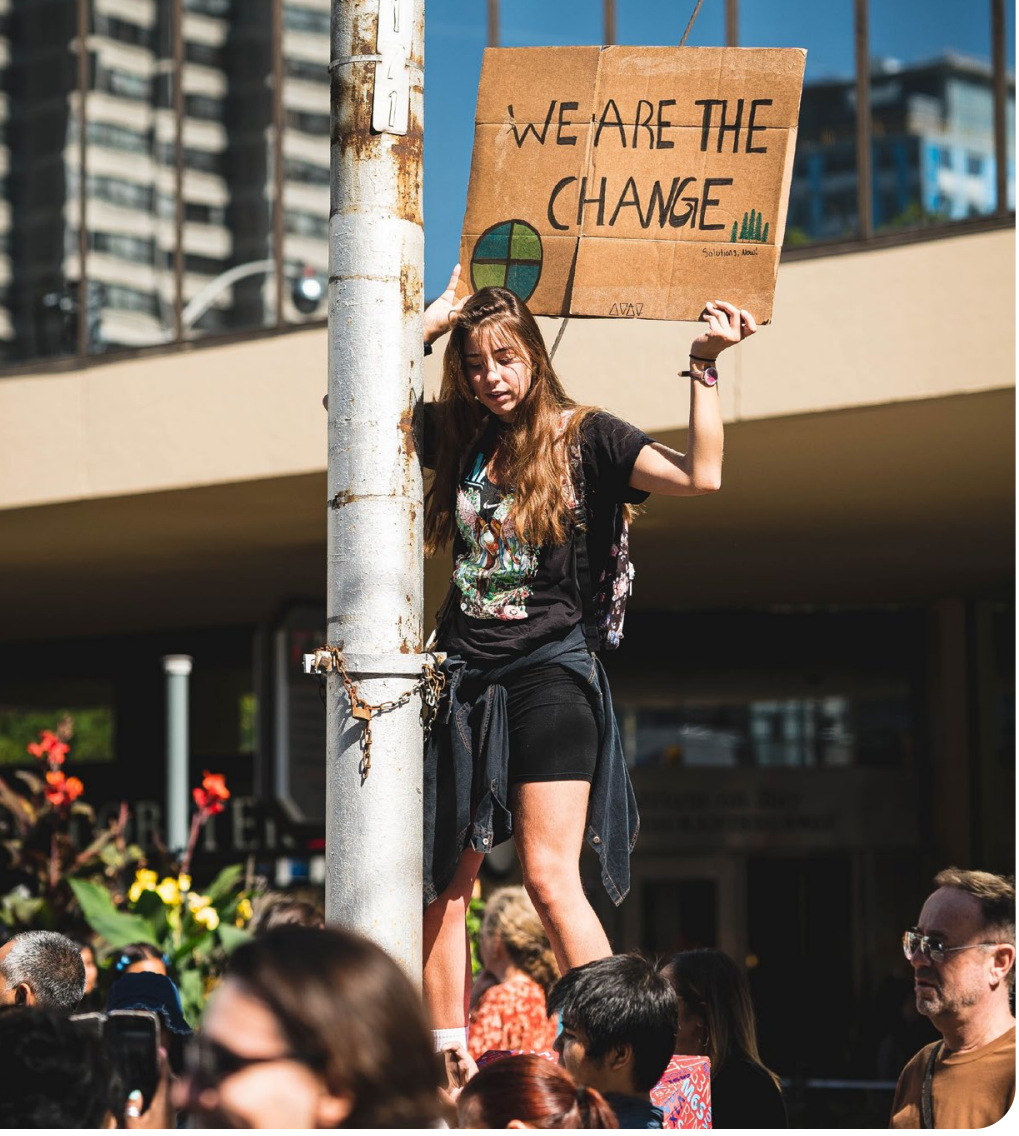

The GST has the mandate to enhance international cooperation for climate action in multilateral settings or in regional convenings. The Katowice decision includes reports from international institutions and regional groups in the sources of input ${ }^{45}$ but is silent on how to engage them in the process.

These suggestions build on lessons from previously established review processes, such as the Structured Expert Dialogues and Talanoa Dialogue. They have the immediate effect of broadening participation, but ultimately aim to better equip the Parties with what they need to engage equitably in the process and shape the outcome. Each suggestion widens the space for developing country Party voices to be heard, instead of leaving the inputs and process to be heavily dominated by developed country Parties. The engagement suggested in Box 4 would be conducted both virtually and in person to secure broader participation.

\section{Making the Outputs Politically Impactful}

The third component will be the most consequential because refining GST outputs will determine the extent to which the GST will inform the revision and enhancement of climate action, support, and international cooperation. Certainly, the quality of the outputs of the third compo-

nent is dependent on ensuring quality inputs and assessment, within the bounds of the guidance provided by the Katowice decision. However, the format and content of the output from the three components remains largely undefined by the decision text. Hence, to fulfil the objectives and functions of the GST it is important to establish processes to ensure that the outputs (especially of the third component) carry political weight and are perceived as legitimate.

The Katowice decision establishes that consideration of outputs will consist of "high-level events" (in the plural) to discuss the findings of the technical assessments and their implications. But the format of the output is not clearly defined, and a clear process will be necessary to ensure that the findings of the technical dialogue are effectively presented, discussed, and reflected in the output. Moreover, the Katowice decision provides no guidance on what might occur after the GST to ensure that it drives ambition and influences in-country NDC enhancement processes. The two-year gap between the end of the third component and the COP, when announcements of revised NDCs are expected, could be used to translate the outputs of the GST into the desired outcomes (Northrop et al. 2018).

The format of outputs suggested in Box 5 could create the foundation for a clearer road map following the GST. Ensuring both technical and political outputs from the third component will make it easier for national stakeholders to work toward the concrete enhancement of action and support, as well as communicate the GST output to a wider audience-the many stakeholders who must be engaged to achieve the long-term goals of the PA.

The outputs of the third component enumerated in the Katowice decision ${ }^{46}$ would presumably match the structure of the sequential discussions of the GST to ensure that they capture the full scope of the GST and produce recommendations on the full set of necessary climate actions and support. The technical output should provide policy-relevant information to inform national policymaking, and guidance and orientation that can drive national change toward achieving the Paris goals. The emphasis should be on solution-oriented outcomes, opportunities, best practices, and synergies with the broader development agenda that can be suited and adapted to different circumstances, rather than only on gaps and weaknesses (Obergassel et al. 2019). 


\section{SUGGESTIONS TO MAKE THE OUTPUTS POLITICALLY IMPACTFUL}

\author{
CLARIFY THE PROCESS TO DELIVER THE OUTPUT OF THE \\ THIRD COMPONENT: \\ - Spread the high-level events throughout the two weeks of \\ the COP: \\ Organize a high-level dialogue between Parties and \\ stakeholders to discuss the implications of the findings of the \\ technical assessment. \\ Discuss each SYR produced from the technical dialogue in \\ a dedicated high-level event, with loss and damage and \\ response measures being considered accordingly. \\ - Livestream the high-level events for transparency. \\ - Ensure high-level participation: To ensure that the GST's \\ outputs are taken up at the national level and translated into \\ concrete ambition enhancement, it will be important to secure \\ the participation of heads of state and government (HoSGs) and \\ ministers from all countries at the COP where the GST's outputs \\ are considered. HoSGs and ministers could be pressed to give \\ a strong renewed political signal of commitment to the PA, \\ including pledges to take up the output of the GST to guide the \\ revision of their NDCs. The COP presidencies would need to take \\ on diplomatic outreach early on to make this happen.
}

FORMAT FOR THE OUTPUTS OF THE THIRD COMPONENT:

- A formal CMA decision fully endorsing all the outputs of the GST; urging Parties to take all GST outputs into consideration when revising their NDCs; and inviting the work of the IPCC to inform future GSTs and fill gaps identified during the current GST.

- A declaration by stakeholders (with or without Parties) as an output of the high-level dialogue events described above.

- Detailed technical summary reports from the high-level events produced by the secretariat with the assistance of the SB chairs. These should capture key messages and recommendations of the high-level thematic events; identify options; and highlight best practices, lessons learnt, and recommendations.

- A final set of high-level recommendations and summary of key political messages, thematically structured, which could include recommendations for strengthening actions and scaling up support, could deliver strong messages to attract the public scrutiny that will effectively influence national and subnational agendas.
A wide and effective stakeholder mobilization throughout the GST would foster greater cooperation between governments and stakeholders; keep the political momentum, public awareness, and support around the action and support; and build the international cooperation required to achieve the long-term goals. Specifically, in the third component expert participation will enhance the legitimacy of the outputs in the eyes of the public and media, as experts and scientists would safeguard the technicality and scientific robustness of the assessment over the possibility of politically negotiated outputs.

\section{Translating Outputs into Outcomes}

The PA ambition cycles provides a two-year time period between the end of the GST process and the COP at which enhanced NDCs are expected to be announced. Crucially, for the GST to succeed in ultimately spurring enhanced climate ambition, this time should be used astutely to ensure that its outputs are translated into the desired outcomes. Here, we distinguish between the outputs produced throughout the GST process and the outcomes that the GST is expected to achieve (Northrop et al. 2018).

The Katowice decision falls short of providing guidance for processes and events to make the best use of the time period after the GST cycle has been completed. Currently, the assumption is that Parties would undertake national technical and policy work over the course of the two years following the GST, using the outputs of the GST to inform the enhancement of their climate action and support. But it cannot simply be assumed that the GST will live on for two years after it ends with relevance to national decision-making. The use of the two-year period after the process ends will be instrumental to encourage or pressure countries to unpack the GST output in support of the concrete enhancement of action and support, as well as to communicate the output beyond the individu- 
- Building political momentum within the process: Building a thoroughly participatory process that engages stakeholders beyond the Parties will help build up the political momentum within the GST that can trigger nationally enhanced ambition. Technical and political cooperation based on the GST's outputs could continue during the two years between the third component of the GST and the next round of NDCs. This could foster buy-in and engagement from all stakeholders in national NDC revision processes.

- Leveraging both technical and political processes will help the GST become nationally relevant and ensure that key messages and recommendations are communicated to national and subnational decision-makers. The United Nations General Assembly or United Nations Secretary-General summit, for example, could be a venue to explain how the output of the GST is guiding NDC revisions and broader sustainable development planning and implementation processes. National and regional appraisals of the GST output could discuss the sectoral, subnational, national, and regional implications of the collective assessment of progress as part of the preparation of successive NDCs.
- Greater interaction (at the local, regional, and global level) could be sought between UNFCCC bodies and other international institutions like the World Bank, regional banks, IMF, IRENA, FAO, WHO, ICAO, IMO and the 2030 Agenda for Sustainable Development, in order to create more ownership and advance the impact of the GST.

- The COP presidencies that come after the end of the GST and before the revised NDCs are announced could take on the heavy lifting of translating the GST outputs into working agendas, through the High-Level Climate Champions. This would enable a deeper dive into implications of the sectoral challenges and opportunities at the regional level, for example.

- Role for observers: Observers can carve out a role for themselves to complement the GST process and ensure that the collective exercise can still be used to inform action at the national level. For example, observers can work to develop, collect, and synthesize country-specific, actionable recommendations on mitigation, adaptation, and finance (Höhne et al. 2019) and engage at various levels-for example, governmental, technical, and private sector. National and local case studies, where climate action and support are strongly linked to national benefits and policy improvements, could be constructive.

The first information-collecting component will be hampered by information and data gaps, which will have to be identified and redressed when possible. ${ }^{47}$ The second technical analysis and assessment component will have to draw conclusions on the basis of both the information available and the data gaps and their implications. The GST itself will not be able to fill these information gaps and will rely on different organizations to produce the relevant data. However, difficulties might arise in convincing Parties to accept data that they have not submitted themselves. Nevertheless, an understanding of the information required and areas lacking that information can help steer the preparation, collection, and consideration of such information. This is important since the third component will have to develop politically relevant high-level recommendations from the information assessed, as well as from the gaps assessed, and should highlight the need for enhanced research and support efforts to address these gaps. 
The GST may also look to the constituted bodies of the UNFCCC to help fill these gaps and provide crucial information on specific areas. For example, the technical work performed by the Standing Committee on Finance, the Adaptation Committee, and the reports and assessments produced can contain further knowledge on the progress made on the long-term goals on finance and adaptation, respectively. Further clarity is needed on what role the constituted bodies can play in the GST process. ${ }^{48}$

Observers to the GST process may be able to contribute to filling data gaps, especially in the first component of the process. They could synthesize information from outside UNFCCC sources, and complement the UNFCCC's understanding of some aspects of mitigation, adaptation, and finance. Observers could also contribute to building common understanding on several issues where there is currently no consensus in the UNFCCC. This could include, for example, financial support to tackle loss and damage induced by climate change. Observers could also build on the GST's recommendations for achieving the long-term mitigation goals and develop national-level sector-specific road maps for decarbonization, which would contribute to enhancing ambition and implementation.

This section identifies gaps and proposes a range of suggestions both content-specific and cross-cutting for each thematic area. The suggestions looking at how the GST can provide policy-relevant assessments through its outputs, in spite of information gaps and uncertainties, will be relevant for negotiators, policymakers, and the UNFCCC secretariat. The suggestions that flag ways to enhance the collection, generation, and analysis of necessary information will be more relevant for think tanks, policy research institutes, and other relevant organizations working to fill information gaps. They can also raise awareness among the negotiators and policymakers so that they engage in and effectively support the GST process moving forward.

\section{Collective Progress toward Achieving Long-Term Mitigation Goals}

Abundant mitigation-relevant information exists that can feed into the GST. Technical and economic information is typically quantitative and can be readily found in data sources for energy use, economic activity, and land use. Data are generally available at both the global and country level through sources like United Nations Environment Programme (UNEP) Gap Reports, IPCC reports, and national GHG inventories. It is likely that the GST will focus primarily on quantitative assessments of the questions "where are we" and "where do we want to go," reiterating the well-researched gap between national actions and what is needed to meet the long-term goals (Northrop et al. 2018).

Mitigation information shortfalls and uncertainties relate to the diversity and divergence of information on how to close the emissions gap to achieve the longterm mitigation goals and how to fairly distribute efforts across sectors and countries over time (Clark and Hultman 2020). Further elaboration of what a future lowcarbon world looks like, and what it would mean for shorter-term NDCs, is also necessary. Some actions and measures are obvious, such as the broad need to transition to renewable energy, enhance energy efficiency, and reduce industrial, agricultural, and deforestation emissions, but near-term targets in these areas, particularly at the country level, remain unclear. In addition, most of the national decisions pertaining to setting near-term targets have long-term consequences and need careful judgment (Clark and Hultman 2020). There are also gaps linking mitigation action to the avoidance of loss and damage, and to unintended socioeconomic consequences of mitigation action.

Information is lacking or hard to obtain on the societal dimensions of mitigation, which limits the GST's ability to answer questions on how to increase ambition (Clark and Hultman 2020). Socioeconomic information could provide insights into societal readiness to undertake mitigation action consistent with the Paris goals, current rates of behavioral change, and the institutional changes that might be needed. This kind of information could include key barriers to mitigation, such as public opinion, power dynamics, or institutional structures.

With these mitigation information gaps and uncertainties in mind, a key task for the GST will be to strengthen the world's knowledge and understanding of how we get to a decarbonized world by 2050 and identify opportunities and challenges to get there. To adequately assess progress to that end, the GST will need to look beyond the commitments made in the NDCs, since they may not fully capture all the efforts taking place globally. Commitments made by non-state actors, subnational entities, businesses, and under other international treaties like the Montreal Protocol, or the IMO (Northrop et al. 2018) will also be relevant. 


\section{SUGGESTIONS FOR ASSESSING PROGRESS TOWARD LONG-TERM MITIGATION GOALS}

\section{BASED ON THE INPUTS, THE OUTPUTS OF THE VARIOUS COMPONENTS OF THE GST COULD:}

- Include a compilation and synthesis of identified gaps ${ }^{\mathrm{a}}$ in the current NDCs and barriers to the achievement of the longterm goals.

- Answer the question "how do we get there" by

a) aggregating information that can be acted upon by Parties, such as policy options moving forward, best practices, lessons learned, and technologies with high mitigation potential

b) understanding emissions drivers (extracted from IPCC and country reports)

- Highlight links with loss and damage and response measures through:

a) how the achievement of the long-term mitigation goals is linked to efforts to avert, minimize, and address loss and damage.

b) instances where mitigation action has led to unintended socioeconomic costs, and provide holistic, sectoral cost-benefit analyses to potentially uncover co-benefits of mitigation action. Such all-inclusive cost-benefit analysis could be undertaken in tandem with the existing Forum on Response Measures. The GST can potentially turn the impacts agenda around, and showcase those co-benefits as a driver of ambition (Obergassel et al. 2019).

- Showcase examples of stakeholder action that falls outside the NDCs, possibly at the sectoral level, and include efforts

a Emerging from different analytical sources.

${ }^{\mathrm{b}}$ This is referred to as an ambition loop. See: https://ambitionloop.org/.

${ }^{c}$ Again, produced or emerging from different analytical sources.

${ }^{d}$ Article 4.1 of the PA. made by non-state actors, the private sector, subnational entities, and under international treaties like the Montreal Protocol, or the IMO. This would shine a light on options for greater ambition and could push governments to follow transition pathways on which some stakeholders have already embarked. ${ }^{b}$

The GST could:

- Consider disaggregated assessments of mitigation trends, opportunities, and barriers down to the sector level. ${ }^{\mathrm{c}}$ It could also identify sector-specific opportunities, and provide recommendations (supported or not by sectoral road maps) on how to achieve the long-term mitigation goals by enhancing ambition and accelerating implementation.

- Include an assessment of GHG peaking and specification of the timing of the balance between the anthropogenic sources and removals (Northrop et al. 2018). ${ }^{d}$

- Support and guide a discussion on equity and ambition. At the heart of the climate negotiations are the questions on whether the NDCs are in line with equity and Common but Differentiate Responsibilities (CBDR-RC) and whether they reflect the "highest possible ambition." A common understanding is that equity is fundamental to the success of the GST, if not the PA as a whole (Hohne et al. 2019).

- Provide space to share views or develop a common vision on what a well-below $2^{\circ} \mathrm{C}$ or $1.5^{\circ} \mathrm{C}$ warmer world would look like, based on qualitative and quantitative scenario analyses and other types of socioeconomic research. 
Collective Progress toward Achieving Long-Term Adaptation Goals

The long-term adaptation goals ${ }^{49}$ of the PA are expressed in qualitative terms, which makes taking stock of collective progress toward their achievement more complex. Information about adaptation is also less advanced than information about mitigation. The data sources relied on by the GST include IPCC reports, country submissions of the adaptation communications to the UNFCCC, adaptation-related information contained in the BTRs, NAPs, and adaptation components of the NDCs.

The challenges to the GST fulfilling its mandate related to adaptation stem primarily from the qualitative nature of the long-term goals:

- Most obvious is the lack of a commonly understood definition of an effective or "adequate adaptation response." This is because of the long timelines associated with adaptation, uncertainty associated with impacts, and the context specificity of adaptation needs and related progress (Northrop et al. 2018).

- Adaptation tracking, monitoring, and evaluation is hampered by the shortage of a common set of metrics and indicators to measure reductions in climate vulnerability or improvement of adaptive capacity. Developing countries also face capacity constraints in carrying out monitoring and evaluation (Northrop et al. 2018).

- The way the global goal on adaptation is prescribed ${ }^{50}$ will affect how sustainable development will be taken stock of as part of the assessment of progress. This will need to be taken into account for the preparation of relevant research, analysis, as well as the collection and assessment of that analysis under the GST.

Despite challenges, the GST could help clarify what needs to be tracked and propose how to track it to measure progress on adaptation that encompasses the entirety of Article 7 of the PA. By highlighting inadequacies in the current adaptation response through an assessment of the collective progress on NAPs, for example, the GST could raise the profile of adaptation relative to mitigation on national and international agendas. This could help take stock of the strength of international cooperation in the context of Article 7.7.51 Furthermore, the results of these assessments could respond to Article

\section{SUGGESTIONS FOR ASSESSING PROGRESS TOWARD THE LONG- TERM ADAPTATION GOALS}

The GST could:

- Enhance assessment by identifying nationally relevant qualitative data on the state of adaptation efforts, make an inventory of national-level experiences and priorities, and assess how to enhance adaptation implementation.

- Identify collective capacity-building and technology needs to inform future capacity-building initiatives and research and development efforts (Northrop et al. 2018), as well as highlight best practices and lessons learned from successful adaptation implementation efforts.

- Provide a collective assessment of adaptation efforts at the sector level, which would involve compiling information on the various kinds of adaptation actions being pursued in different sectors and in different national, environmental, and socioeconomic contexts. It would look at whether sectoral adaptation needs are being met, and identify barriers. While quite challenging, disaggregating the adaptation assessment at the sector level would also facilitate an assessment of sectoral adaptation costs, which can then be compared with the funding provided for adaptation. This would enable an assessment of the extent to which adaptation is widespread throughout economies and societies. ${ }^{62}$

- Define "adequate." The GST can be methodologically focused to better understand the meaning of an "adequate" adaptation response in a $1.5^{\circ} \mathrm{C}$ warmer world. The process could then contribute to determining the "adaptation gap," and whether current adaptation actions, and financial and technical means allocated to them, are enough to meet global needs in terms of governance, policy, legislation, finance, knowledge, and capacity.

$7.6^{52}$ by potentially directing more funding toward adaptation, especially to developing country Parties. Regarding equity, the GST could look at whether adaptation efforts are country-driven, gender-responsive, participatory and transparent, and focused on the most vulnerable groups, communities and ecosystems, in line with Article 7.5 (Holz et al. 2019). ${ }^{53}$ 
Collective Progress Toward Achieving the Long-Term Financial Goal

Given the depth and urgency of the transition required to meet long-term mitigation and adaptation goals, it is critical that the GST assess progress on two core, interrelated topics of the UNFCCC: the mobilization and provision of support to developing countries to mitigate and adapt to climate change, and the consistency of all financial flows with the Paris climate objectives (Watson and Roberts 2019). The assessment of financial flows-including, but not limited to means of implementation and support-is required to assess progress toward the Paris goals.

A number of inputs are available to address these issues. For example, the Katowice decision identified the Biennial Assessment and Overview of Climate Finance Flows (BA) as a formal input into the financial discussions of the GST. The BA includes information related to the commitment by developed countries to mobilize US $\$ 100$ billion annually in climate finance for developing countries between 2020 and 2025, the breakdown of finance between mitigation and adaptation, the effectiveness of climate finance, and, every four years, a mapping of information relevant to Article 2.1(c) of the PA. Other inputs into the GST will include voluntary submissions from Parties, relevant reports from regional groups and institutions, and submissions from stakeholders and UNFCCC observer institutions. Finally, the IPCC Working Group III has also provided analysis on finance and investment which could be further leveraged (Gupta et al. 2014).

However, there are a number of information gaps and challenges that will make it difficult for the GST to take stock of finance:

- Definitional challenges make it difficult to assess progress. The financial goal set in Article 2.1(c) of the PA provides no definition of what "consistent with a pathway toward low-greenhouse gas emissions and a climate resilient development" means in practice.

- The Katowice decision designates one of the three thematic areas for the GST as focusing on means of implementation and support. This has created some uncertainty about how the GST will adequately assess progress related to the long-term goal set out in Article 2.1(c) of the PA, which covers the consistency of financial flows.
- The ETF does not require Parties to provide information on broader financial flows beyond means of implementation and support, nor on their efforts to make financial flows consistent with the PA.

- Only developed country Parties are required to report the support provided and mobilized for developing countries in BTRs, while others are only encouraged to do so. The data reported are neither consistent nor complete, particularly at the collective level (Obergassel et al. 2019).

We offer a number of suggestions to guide the outputs of the GST.

\section{Cross-Cutting Issues and Suggestions}

This section analyzes the selection and use of indicators to facilitate the assessment of progress and consideration of equity in the GST.

\section{Selection and Use of Indicators}

The technical assessment component of the GST will involve the use of indicators to assess progress against targets in order to produce outputs that are politically relevant for the third and final consideration of outputs component. The selection of those indicators, and the indicators themselves, will be powerful tools to make the GST more robust "in the light of equity," 55 bearing in mind that the nature of the GST precludes the assessment of national-level commitments.

This section highlights the intersection between the choice of indicators and the need to run a global assessment equitably, in order to ensure the GST's legitimacy in the multilateral process. Currently, the Katowice decision is silent on how indicators can be used to evaluate global efforts equitably. Working toward a common understanding of the kinds of indicators that could be useful in evaluating the fairness of national climate action and support, within a process that is constrained to operate only at the collective level, would be critical to allowing the GST to perform its ambition-driving and accountability functions. While this issue brief does not make specific recommendations on which indicators to choose, it highlights a research opportunity for think tanks, and academic and civil society organizations to produce data that illustrate what could be deemed as equitable efforts. 


\section{SUGGESTIONS FOR OUTPUTS FOR ASSESSING PROGRESS TOWARD THE LONG- TERM FINANCIAL GOAL}

The GST could do the following:

- Take stock of emerging analysis on financial commitments: First on where developed countries stand collectively in terms of delivering $\$ 100$ billion annually by 2020 and until 2025. Subsequent GSTs could do the same for the new collective mobilization goal to be agreed by 2025. This would contribute to transparency and accountability, and hopefully push Parties to better deliver.

- Encourage Parties to voluntarily include information on activities related to Article 2.1(c) in future submissions such as NDCs and/or BTRs, which would be a means to ensure that data on financial flows are automatically reflected in the GST (Whitely et al. 2018). Such efforts could build on the work undertaken by the Standing Committee of Finance, which could be further mobilized to provide additional guidance.

- Identify needs and gaps in policies and support (including the adequacy and effectiveness of adaptation support), and assess the balance between financial resources for mitigation and adaptation, and efficient access to financial resources (Northrop et al. 2018).

- Build consensus on what "Paris-compatible financial flows" means by assessing the information related to Article 2.1(c) of the $P A$, and highlighting where financial flows are not consistent with the Paris goals; for example, finance for highemissions activities.

- Contribute to policy learning by assessing the effectiveness of policies and support to align financial flows in accordance with Article 2.1(c). Aggregate and share best practices and lessons learned from countries' financial policies and regulations, fiscal policies, and public finance (Watson and Roberts 2019).

- Discuss how much climate ambition can be enhanced through alignment and mobilization of finance based on emerging analysis. Relatedly, the discussion and its output could highlight the virtuous circle by which investments in specific climate-friendly technologies, financial tools, and policy mechanisms under current NDCs have brought the costs of climate action down, generated socioeconomic benefits, and unlocked additional opportunities.

- Make recommendations to policymakers, regulators, and investors for ways to better align finance with climate goals, informing Parties about potential support needs and commitments to include in their future NDCs (Watson and Roberts 2019).
We also recognize that it will not be easy for Parties to come to an agreement on the set of indicators to use in a systematic fashion. Recommendations (even on a voluntary basis) could also emerge from the way Parties justify how their contributions are fair and equitable.

Most of the indicators widely used today are technical and economic and provide valuable insight on physical and economic outcomes. Technical and economic information that lends itself naturally to quantitative metrics will be useful for the quantitative assessments of the questions "where are we" and "where do we want to go?" But qualitative assessment of collective progress toward the achievement of long-term goals is also needed to bring more granularity and tell a local, regional, or sectoral story and, therefore, facilitate public scrutiny to ensure accountability of governments' level of climate ambition and action. ${ }^{56} \mathrm{~A}$ mix of technical, economic, and societal indicators would, therefore, enable the balanced assessment necessary for the GST to fulfill its functions of pacesetting, driving ambition, sending signals, and holding countries accountable.

Socioeconomic information is less easy to aggregate and synthesize, and thus less easy to address through indicators (Clark and Hultman 2020). Clear indicators are lacking to measure the societal and institutional transformations associated with achieving carbon-neutral economies, including indicators relevant to gender, and inclusive and participatory processes. In addition, unless information and indicators are standardized and made mandatory, it will not be possible to assess progress across countries or globally. Defining the indicators will both help countries and subnational entities track and address the ambition and degree of equity of their action, and act as a pressure point. An evaluation of the 


\section{SUGGESTIONS TO GUIDE INDICATOR SELECTION AND FACILITATE EQUITY}

Indicators:

- Indicators could be selected at the start of the technical dialogue, during the IPCC-SBSTA dialogue mandated by the Katowice decision to enable focused scientific discussions and to enhance coordination on the GST. ${ }^{66}$ The IPCC brings together credible groups of experts with geographical, gender, and expertise balance. This meeting should help advance our common acceptance of global measures of progress in the thematic areas, as well as our common understanding of the kinds of indicators that could be useful in evaluating the fairness of national climate efforts.

- Indicators would have to explicitly address the Paris goals (e.g., total global emissions and how they compare with the $1.5^{\circ} \mathrm{C}$ target; expected year of global emissions peak; rate of warming based on aggregation of NDC targets, if achieved; drivers of emissions; and non-emissions-based and more qualitative indicators).

- Qualitative narratives could be useful in cases where progress may not easily be captured by quantitative indicators; for example, information on key barriers to mitigation falling outside the scope of international finance and technology transfer, such as public opinion (Clark and Hultman 2020) and the social dimension.

- Grouping countries into tiers (Northrop et al. 2018) against indicators of responsibility and capability, such as current and historic per capita emissions or GDP could partly overcome the limitation imposed by the mandate to address only collective progress. Efforts to identify and possibly select equity- (coupled with development-) related indicators could help better take into account countries' levels of development.

- Sectoral indicators could be used to rate individual sectors on their progress toward achieving net-zero emissions. Global progress could then be measured against those sectoral indicators (Obergassel et al. 2019). Information from individual countries could be used anonymously (Jeffrey et al. 2019).

Ways to facilitate equity:

- The assessment under the GST can draw on the explanations of equity included in Parties' NDCs, aggregating those into a commonly accepted framework for recognizing the fairness and adequacy of a contribution (Winkler 2020).

- Selected indicators could include equity in relation to individuals, inter- and intra-generations, race-ethnicity, countries' historical responsibility, countries' capacity to implement climate solutions, countries' access to basic needs and rights, and countries' vulnerability to climate change (AlZahrani et al. 2019). This information could be compiled through an independent analysis produced by think tanks or other nongovernmental organizations.
2023 GST process and its outcome could result in the refinement and adjustment of indicators for the second GST in 2028.

\section{Ensuring Consideration of Equity}

The inclusion of equity in the PA's mandate for the GST was a hard-won agreement considered vitally important by many Parties. Parties have specified that the thematic areas must be treated in a "balanced, holistic and comprehensive manner." ${ }^{77}$ Such treatment will be critical for the robustness of the GST, which will only be accepted as equitable and legitimate by developing country Parties if it is seen as addressing their long-held concerns that are not always mitigation-centric. This is a pivotal yet sensitive aspect of the ambition mechanism that the GST aspires to be. More effort is needed if equitable approaches and considerations are to deliver tangible outcomes and spur a just transition toward climate-resilient and zero-carbon economies and societies.

Equity should, therefore, be reflected across all issues covered by the GST. Ideally, the GST outputs would address the extent to which countries are fulfilling their equitable contributions to global climate action and provide guidance on the appropriate levels of mitigation ambition, adaptation action, and means of implementation and support that individual countries should make. However, this is a sensitive issue. As we know, the mandate of the GST is to assess collective efforts made toward achieving the Paris goals, making it impossible for the GST to provide assessments that would indicate equitable effort-sharing at the national level, let alone within coun- 
tries. It is difficult to evaluate equitable contributions if the discussions do not disaggregate the assessment to the country level, not to mention that there is no global consensus on how to measure an equitable burden or effort share regarding mitigation, adaptation, and means of implementation and support aimed at achieving the Paris goals. It is also unclear how the effects of climate actions on sustainable development priorities, the eradication of poverty, reduction of inequality, and loss and damage can be measured, or how unintended adverse impacts of climate policies can be reflected in the GST. This issue brief acknowledges the importance of these issues but cannot do justice to them.

\section{Operationalizing Suggestions Related to Information Gaps and Uncertainties}

The information gaps and uncertainties are cross-cutting and will surface in all three components of the GST. The GST's ability to collect all the information it requires to cover its broad scope can be enhanced if the process is made more equitable by encouraging input from developing countries and stakeholders (Boxes 2 and 3), and improving their access to information. Refining SBSTA mechanisms to identify and redress information gaps (Box 4) and providing adequate resources will also enhance information flow to the GST.

Aggregating the inputs collected from the first component into a format that is usable for the second component is necessary for the technical dialogue to take stock and assess collective progress toward the long-term goals. The input into the GST should also be made publicly available, with set opportunities for stakeholders to review, comment on, and complement the input, in particular, the transparency reports submitted by parties (Obergassel et al. 2019).

Box 10 suggests ways to select indicators that will enable the technical dialogue to move from exchanging views, information, and ideas ${ }^{59}$ to effectively taking stock and assessing collective progress with a view to producing output that Parties can use to enhance climate action and support. Those indicators will enable the data and information collected in the first component to tell the story of the progress made and by whom, whether progress is on track to achieve the long-term goals, and where the opportunities and challenges to do more lie.
It will also be critical for independent bodies like the iGST to ensure their membership is fully reflective of geographical balance, generate new research where there are data gaps, or synthesize available information that may be beyond the capacity of the GST, such as information related to nongovernmental action. Non-Party stakeholders and independent bodies like the iGST could organize regional, national, or thematic GST-related dialogues of their own in addition to participating in the technical dialogue under the GST process. This would require the outputs from the relevant components to be made publicly available so that they can be discussed in such workshops. The report-back of these events could happen through SBSTA and/or the High-Level Climate Champions, and these events could also be broadcast. Boxes 2, 7, 8 , and 9 of this issue brief suggest ways to aggregate the information collected into robust output, and the kinds of assessments the GST could make and reflect in its outputs, based on the information collected as well as on the gaps identified.

The outputs of the third component must send strong signals to the world about where it stands in relation to achieving the Paris goals, and highlight the gaps and challenges. More importantly, outputs should communicate best practices and opportunities to reach the goals, to catalyze greater efforts from governments and other forums (Obergassel et al. 2019). This can be achieved by producing solution-oriented outcomes, and by identifying synergies with the broader development agenda that can be adapted to different circumstances.

Box 11 suggests how the outputs might be made politically impactful, including ways in which the wealth of output produced by the technical assessment can be effectively presented, discussed, and considered, address the information gaps identified in this issue brief, and catalyze solutions. To maximize the impact of the third component, it will be important to involve experts from nongovernmental organizations, in addition to Party representatives, to prevent overly politicized and negotiated outputs. Outside involvement will help maintain scientific robustness and legitimacy, while enhancing the visibility of the GST in the eyes of the public and media, spurring enhanced climate action. It may also be useful to generate and communicate two sets of outputs-technical and political. In these outputs, Parties would be well placed to invite the work of the IPCC to inform future GSTs and fill gaps identified during the current GST. 
ADDITIONAL SUGGESTIONS TO MINIMIZE INFORMATION GAPS AND UNCERTAINTIES

\author{
There are mainly three ways in which the suggestions made in \\ this issue brief related to information gaps and uncertainties can \\ be implemented: \\ - Refining and implementing mechanisms both within the GST \\ proper and throughout the wider UNFCCC architecture to ensure \\ that information gaps are identified and addressed, allowing for \\ the broader participation and engagement of Parties and stake- \\ holders in the process, and ensuring that Parties are equipped \\ with all the materials they need to engage equitably throughout \\ the GST process.
}

- Implementing guidance on the format, structure, and types of outputs of the GST will help address content-related matters so that the outputs are reflective of the assessments made and carry political weight.

- Role of observer organisations: Non-Party stakeholders and independent bodies like the iGST can play a crucial role in filling data gaps and synthesizing information that falls outside the scope of the mandated GST input. Stakeholders can discuss the outputs of the relevant components through thematic GSTrelated dialogues and report back to SBSTA.

\section{CONCLUSION}

In December 2018, in Katowice, countries agreed on a set of procedures and modalities to bring the PA to life. Known as the Paris Rulebook, this set of internationally agreed upon requirements allowed countries to set their own level of commitments through voluntary climate action and support pledges, but embedded them in an international accountability framework and a ratchet mechanism in the hope of increasing global ambition.

Whether governments will be able to go beyond their comfort zone and express ambitious aspirations based on tough science-based decisions remains to be seen. For the PA to catalyze change at the scale and pace required, the GST will need to mobilize compelling data, generate international and domestic pressure, and create political momentum behind the climate pledges and review processes. The GST processes in 2023 and 2028 must be both decisive and prompt bold and transformational action and support.

This issue brief reviews how the GST, based on architecture adopted in Katowice, can contribute to achieving the Paris goals and fulfil four important functions: pace-setting, driving ambition, holding countries accountable, and sending signals with supporting guidance. It highlights a number of gaps that hinder these functions, both in terms of process and substance (information content).
This issue brief also shows the great potential that lies within the bounds of the GST and the opportunities to strengthen the process before its first test. It includes a number of suggestions to make the GST more fit for purpose, including ways to facilitate a thorough, effective, equitable, and timely assessment of country progress by maintaining the fragile balance struck in the negotiations regarding the depth of the considerations on the longterm goals and thematic areas. It also offers insights on how to make the process as equitable and inclusive as possible. These suggestions can be reviewed against the GST timeline in Appendix C.

Non-state actors can play an important role in shaping the process and outcome of the GST through their participation and inputs. The limitations inherent in the GST mean that several of the recommendations could be picked up by international think tanks, research organizations, or civil society, and still contribute to tapping the GST's full potential. These and other observers of the GST process can reduce many of the data gaps by contributing relevant analysis of environmental and economic issues, but also social and behavioral data and trends, which have been insufficiently studied. Observer organizations could also synthesize relevant information from sources outside the UNFCCC, building common understanding on issues where there is currently no consensus in the UNFCCC, and participating in the conversation during the various components of the GST. 


\section{APPENDIX A. TIMELINE OF THE FIRST GST}

\section{TIMELINE OF THE FIRST GST}

\begin{tabular}{|c|c|c|}
\hline Dates & UNFCCC and IPCC Agenda & GST Agenda \\
\hline April 2021 & IPCC WG1 & \\
\hline June 2021 & SB 54 & \\
\hline July 2021 & IPCC WG3 & \\
\hline October 2021 & IPCC WG2 & \\
\hline $\begin{array}{l}\text { November/ } \\
\text { December } 2021\end{array}$ & SB55/COP27 & $\begin{array}{l}\text { - SBs produce guiding GST questions (per paragraph } 7 \text { "one session of the } \\
\text { subsidiary bodies prior to the relevant activities under the global stocktake } \\
\text { being carried out") } \\
\text { - SBs complement the non-exhaustive list of sources of input (per paragraph } 38 \\
\text { "at its session held prior to the information collection and preparation compo- } \\
\text { nent of the global stocktake") }\end{array}$ \\
\hline May/June 2022 & SB56 & $\begin{array}{l}\text { Start information collection and preparation component (per paragraph } 8 \text { "will } \\
\text { commence one session before the start of the technical assessment") }\end{array}$ \\
\hline July 2022 & IPCC SYR & \\
\hline August 2022 & & $\begin{array}{l}\text { Cutoff date for submitting GST input-August } 2022 \text { per paragraph } 19 \text { "taking into } \\
\text { account that such inputs should be submitted at least three months before their } \\
\text { consideration in the technical assessment" }\end{array}$ \\
\hline $\begin{array}{l}\text { November/ } \\
\text { December } 2022\end{array}$ & SB57/COP28 & $\begin{array}{l}\text { Start technical assessment [per paragraph } 8 \text { "which will take place during the } \\
\text { two (or depending on the timing of the publication of the Intergovernmental } \\
\text { Panel on Climate Change reports, three) successive sessions of the subsidiary } \\
\text { bodies preceding the sixth session of the Conference of the Parties serving as } \\
\text { the meeting of the Parties to the Paris Agreement (November 2023)"] }\end{array}$ \\
\hline May 2023 & & $\begin{array}{l}\text { End of information preparation component-per paragraph } 20 \text { "Decides that the } \\
\text { information collection and preparation component of the global stocktake will } \\
\text { end no later than six months before the consideration of outputs" }\end{array}$ \\
\hline May/June 2023 & SB58 & $\begin{array}{l}\text { End technical assessment [per paragraph } 8 \text { "which will take place during the two } \\
\text { (or depending on the timing of the publication of the Intergovernmental Panel } \\
\text { on Climate Change reports, three) successive sessions of the subsidiary bodies } \\
\text { preceding the sixth session of the Conference of the Parties serving as the } \\
\text { meeting of the Parties to the Paris Agreement (November 2023)"] }\end{array}$ \\
\hline $\begin{array}{l}\text { November/ } \\
\text { December } 2023\end{array}$ & SB59/COP29 & $\begin{array}{l}\text { Consideration of outputs per paragraph } 8 \text { "(November 2023) during which the } \\
\text { consideration of outputs will take place" }\end{array}$ \\
\hline $\begin{array}{l}\text { November/ } \\
\text { December } 2025\end{array}$ & COP31 & $\begin{array}{l}\text { Per paragraphs } 17 \text { and } 18 \text { "Invites Parties to present their NDCs, informed by the } \\
\text { outcome of the GST, at a special event under the auspices of the UNSG" and } \\
\text { "other related events within and outside the UNFCCC can contribute to the GST } \\
\text { and the implementation of its outcome" }\end{array}$ \\
\hline
\end{tabular}

Note: Due to the COVID-19 pandemic, it is possible that the timing of the first GST will be adjusted. The timeline shown here is what was expected before the outbreak of the pandemic. Source: Based on Katowice decision (UNFCCC 2018). 


\section{APPENDIX B. POSSIBLE GUIDING QUESTIONS FOR THE GST}

This appendix provides possible guiding questions that build on Northrop et al. (2018) and Höhne et al. (2020). A selection of the questions could be used by all components of the global stocktake, including specific thematic and cross-cutting questions (Paragraph 7 of $1 .(\mathrm{CP} / 24)$.

\section{Mitigation}

\section{Where are we?}

- Are all Parties preparing, communicating, and maintaining successive NDCs? (Article 4.2)

- Are all Parties pursuing domestic mitigation measures, with the aim of achieving the objectives of such contributions, (Article 4.2) and can they be considered a major deviation from past activities?

- Are all Parties providing the information necessary for clarity, transparency, and understanding, in accordance with Decision 1/ CP.21 and other relevant decisions? (Article 4.8)

- Are the NDCs in line with equity and CBDR-RC and do they reflect "highest possible ambition" (Article 4.3) given potential costs and benefits?

- Are Parties accounting for their NDCs in the manner outlined in Article 4.13?

- How have long-term low GHG emission development strategies been formulated? (Article 4.19)

- Are sinks, reservoirs of sinks, and reservoirs of GHGs being conserved and enhanced (as appropriate)? (Article 5.1)

- Is the use of internationally transferred mitigation outcomes toward NDCs promoting sustainable development and ensuring environmental integrity and transparency, including in governance, and applying robust accounting to ensure, inter alia, the avoidance of double counting? (Article 6.2)

- Is the mechanism to contribute to the mitigation of $\mathrm{GHG}$ emissions and support sustainable development established and effective? (Article 6.4)

- Is the framework for nonmarket approaches to sustainable development established and effective? (Article 6.9)

- To what extent are Parties providing and receiving international support, and how effective is it?
- What is the aggregated impact of subnational and nonstate actions on the implementation of mitigation actions and ultimately on future global GHG emissions?

- What are the aggregated projected GHG emissions that result from all actions?

-When will emissions peak?

- What is the current trend of drivers of emissions at the country and the sectoral level?

- When do $\mathrm{CO}_{2}$ emissions need to reach net zero?

- When do non-carbon dioxide GHG emissions need to reach net zero?

- When do total GHG emissions need to reach net zero?

- Based on current progress, what is the projected increase in global average temperatures above preindustrial levels?

\section{Where do we need to be?}

- What global emission pathways are consistent with the long-term temperature goal, and what are the associated assumptions?

- What does it mean for mitigation to be conducted in an equitable manner?

- What does a $1.5^{\circ} \mathrm{C}$ warmer world look like on a country and sector level? What would such a shared vision be?

- What is the gap (in global GHG emissions, technology, action, investments) between current progress and scenarios consistent with the long-term temperature goal?

\section{How do we get there?}

- What are the barriers for implementation of further actions, and how can Parties be supported in overcoming them?

- What projects, programs, policies, and institutions are available to close the gap between where we are and where we need to be on a regional, country, sector, and organization level? Which of these have proved successful in the past?

- What are the costs (e.g., mitigation costs, compromises on food and water availability) and benefits (e.g., lower air pollution and better health, energy security, and innovation) of achieving additional reductions at the regional, country, sector, and organization level? 


\section{Adaptation}

\section{Where are we?}

- Are all Parties preparing and reporting successive adaptation communications?

- Are Parties planning and implementing domestic policies and governance structures in support of their adaptation communications and do these enhance adaptive capacity, strengthen resilience, and reduce vulnerability?

- To what extent has adaptive capacity been enhanced, resilience strengthened, and vulnerability reduced with a view to contributing to sustainable development? (Article 7.1)

- How do these advances contribute to sustainable development? (Article 7.1)

- What data and information have been gathered, synthesized, and shared to recognize the adaptation efforts of developing countries? [Article 7.3 and 7.14(a)]

- To what extent is adaptation action incorporating the principles outlined in Article 7.5?

- Are efforts to adapt to climate change being conducted in an equitable manner?

- What evidence exists to indicate that Parties are strengthening their cooperation on enhancing action on adaptation? (Article 7.7)

- To what extent have Parties enhanced understanding, action, and support with respect to loss and damage associated with the adverse effects of climate change?

\section{Where do we need to be?}

- What are the current and projected climate change needs, risks, and impacts?

- What does it mean for adaptation to be conducted in an equitable manner?

- What does the temperature goal in Article 2 require in terms of an "adequate" adaptation response (Article 7.1) considering climate risk and residual damages?

- How adequate and effective is adaptation and support provided for adaptation? [Article 7.14(c)]

- What is required for Parties to avert, minimize, and address loss and damage associated with the adverse effects of climate change?

\section{How do we get there?}

- What are the common technological, social, and financial barriers to adaptation planning, and how can Parties overcome, and be supported to overcome, them? (Article 7.8)

- What is needed to support broader incorporation/application of the principles outlined in Article 7.5?

- In what ways can Parties continue to build on the Cancun Adaptation Framework to strengthen cooperation on enhancing action on adaptation? (Article 7.7)

- What outputs are needed to enhance the implementation of adaptation action? [Article 7.14(b)]

- What policies and institutions at the country and sector level are available to achieve the adaptation actions that are needed? Which of these have proved successful in the past?

- What policies and institutions are available to reduce the risk of loss and damage?

- What are the associated costs and benefits (resilience, avoided damages, other positive effects) of these approaches at country and sector level? 


\section{Where are we?}

- What is the status of financial support (contributions) in implementing the Paris Agreement (PA) and reporting on it?

- To what extent are current financial flows consistent with compatible pathways toward low GHG emissions and climate-resilient development, toward meeting the collective financial goal? [Article 2.1(c)]

- To what extent are countries and other actors mobilizing financial resources, technology transfer, and capacity building in line with the PA's goals in an equitable manner?

- What projects, programs, policies, and institutions are being used to make financial flows consistent with a pathway toward low GHG emissions and climate-resilient development, and how effective are they? [Article 2.1(c)]

- Are developed country Parties providing financial resources to assist developing country Parties in continuation of their existing obligations under the UNFCCC? (Article 9.1)

- Are other Parties providing support voluntarily? (Article 9.2)

- Is the mobilization of climate finance taking into account the needs and priorities of developing country Parties and a progression beyond previous efforts? (Article 9.3)

- Is the provision of scaled-up financial resources achieving a balance between adaptation and mitigation? (Article 9.4)

- Are the institutions serving the PA ensuring efficient access to financial resources through simplified approval procedures and enhanced readiness support for developing country Parties, in particular, for the least developed countries and small island developing states? (Article 9.9)

- What support is being provided to developing country Parties for technology development and transfer, including for strengthening cooperative action on technology development and transfer at different stages of the technology cycle, with a view to achieving a balance between support for mitigation and adaptation? (Article 10.6)

- Are Parties cooperating to enhance the capacity of developing country Parties to implement the PA? Are developed country Parties enhancing support for capacity-building actions in developing country Parties? (Article 11.3)

\section{Where do we need to be?}

- What would it take to make financial flows consistent with compatible pathways toward low GHG emissions and climate-resilient development, in accordance with the goals set out in Articles 2.1(a) and (b), 4.1, and 7.1? [Article 2.1(c)]

- What is the estimated gap between climate finance mobilized, the collective mobilization goal, and pathways that are consistent with the long-term goal?

- Which projects, programs, policies, and institutions are consistent with low GHG emissions and climate-resilient development pathways, and which projects, programs, policies, and institutions are not consistent with such pathways?

- What are the needs and priorities for support of developing country Parties? (Article 9.3)

- How large is the gap between the financial resources provided for adaptation and the financial resources provided for mitigation? (Article 9.4)

- What is the estimated gap between climate finance mobilized, the collective mobilization goal, and pathways that are consistent with the long-term goal?

\section{How do we get there?}

- What are the barriers that prevent financial flows to be consistent with the goals of the PA?

- How can support provided and mobilized be more effective in meeting the long-term goals of the PA?

- What projects, programs, policies, and institutions are necessary to make financial flows consistent with a pathway toward low GHG emissions and climate-resilient development, and how could they enable an increase in ambition? [Article 2.1(c)]

- What policies, investments, and institutional reforms are required to scale up the mobilization of finance, achieve a balance between adaptation and mitigation financial resources, and ensure efficient access to finance? (Articles 9.4 and 9.9) 


\section{Additional Questions Arising from Implementation of the Agreement}

There are additional issues that the GST may have the mandate to consider, even though they don't fit neatly under the three thematic areas:

\section{Where are we?}

- To what extent have Parties cooperated to enhance climate change education, training, public awareness, public participation, and public access to information, recognizing the importance of these steps with respect to enhancing actions under the PA? (Article 12)

- To what extent have Parties implemented Article 13, including the provision of information under paragraphs 7, 8, 9, and 10 and the review process under paragraphs 11 and 12?

- Are efforts on mitigation, adaptation, and support being conducted in an equitable manner?

\section{Where do we need to be?}

- What is required for enhanced cooperation on education, training, public awareness, public participation, and public access to information? (Article 12)

- What reporting and review requirements would be compatible with the long-term goals of the PA?

- What does it mean to implement mitigation, adaptation, and support in an equitable manner?

\section{How do we get there?}

- In what ways can sustainable development reduce the risk of loss and damage? (Article 8.1)

- Has the Warsaw International Mechanism for Loss and Damage collaborated with existing bodies and expert groups under the PA as well as relevant organizations and expert bodies outside the $\mathrm{PA}$ ? (Article 8.5)

- What lessons have been learned about enhancing education, training, public awareness, public participation, and public access to information on climate change? How can they be scaled up? What opportunities are there for additional cooperation? (Article 12)

- How could the barriers for reporting and review requirements that would be compatible with the long-term goals of the PA be overcome?

- How can mitigation, adaptation, and support efforts be conducted in a more equitable manner? 


\section{APPENDIX C. MATCHING SUGGESTIONS FOR AN EFFECTIVE GST TO THE GST'S COMPONENTS}

\section{MATCHING SUGGESTIONS FOR AN EFFECTIVE GST TO THE GST'S COMPONENTS}

Component 1: Information collection and preparation

\section{Component 2: Technical assessment}

SCOPE
Component 3: Consideration of outputs

The internal architecture of the GST needs to be built in order to operationalize the scope so that the GST can assess collective progress toward the long-term goals and avoid a narrow understanding of the three thematic areas of mitigation, adaptation, and means of implementation and support narrowly while providing clarity on how to address loss and damage and response measures. This can be done through:

- Organizing the components of the GST into sequential discussions that would either

$\square$ each consider the implications related to mitigation, adaptation, means of implementation and support, loss and damage, and response measures for each of the three long term goals; or

$\square$ be structured around the long-term goals of the PA and based on the thematic areas, with loss and damage and response measures assessed under each workstream as appropriate, and in light of equity and the best available science.

- A framework supported by a set of guiding questions to look both backward (on progress undertaken to meet the global commitments) and forward (to signal plans and intent to step up climate action and support).

\begin{tabular}{|c|c|c|}
\hline \multicolumn{3}{|c|}{ INFORMATION GAPS } \\
\hline $\begin{array}{l}\text { Mitigation } \\
\text { For the GST to effectively strengthen our knowledge of } \\
\text { how to decarbonize the world by } 2050 \text { it could: } \\
\text { - disaggregate assessment of mitigation trends } \\
\text { down to the sectoral level; } \\
\text { - share best practices and lessons learned on how } \\
\text { to achieve the temperature goal; } \\
\text { - provide more analysis on the link between efforts } \\
\text { on L\&D and unintended socioeconomic costs and } \\
\text { co-benefits; } \\
\text { - showcase stakeholder's action beyond NDCs; } \\
\text { - highlight how societal aspects of mitigation relate } \\
\text { to important barriers to action; and } \\
\text { - provide an assessment of gaps in the NDCs. }\end{array}$ & $\begin{array}{l}\text { Adaptation } \\
\text { The GST can be a useful exercise if its treatment of } \\
\text { adaptation is activity-focused and methodology- } \\
\text { focused to: } \\
\text { - identify nationally relevant qualitative data on the } \\
\text { state of adaptation efforts; } \\
\text { - identify collective capacity-building and tech- } \\
\text { nology needs; } \\
\text { - develop a framework for collective assessment of } \\
\text { adaptation efforts at the sector level; and } \\
\text { - request the SBs to call for information on gaps, } \\
\text { challenges, opportunities, and options related to } \\
\text { methodologies for reviewing the effectiveness and } \\
\text { "adequacy" of adaptation. }\end{array}$ & $\begin{array}{l}\text { Long-Term Finance } \\
\text { The knowledge for means of implementation and } \\
\text { support and consistency of financial flows is scat- } \\
\text { tered. The GST can find ways to: } \\
\text { - build consensus on what Paris-compatible finan- } \\
\text { cial flows mean; } \\
\text { - assess the balance between financial resources for } \\
\text { mitigation and adaptation; and } \\
\text { - assess how much climate ambition can be } \\
\text { enhanced through alignment and mobilization of } \\
\text { finance. }\end{array}$ \\
\hline \multicolumn{3}{|l|}{ 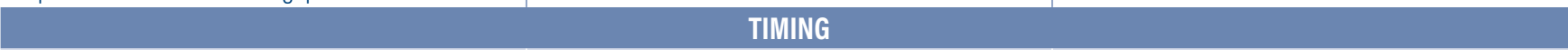 } \\
\hline $\begin{array}{l}\text { To ensure that the timelines for the different compo- } \\
\text { nents of the GST are met and smooth orchestration of } \\
\text { the first component: } \\
\text { - clear deadlines should be set for the preparation } \\
\text { and delivery of outputs of the first component to } \\
\text { feed into the technical assessment seamlessly; } \\
\text { - clear roles should be allocated between UNFCCC } \\
\text { bodies for who will aggregate the large volume of } \\
\text { information collected; and } \\
\text { - linkages between the GST and other processes, like } \\
\text { the transparency framework and the IPCC cycles, } \\
\text { should be ensured so that the GST has the informa- } \\
\text { tion it needs to undertake thorough assessments. }\end{array}$ & & \\
\hline
\end{tabular}




\section{MATCHING SUGGESTIONS FOR AN EFFECTIVE GST TO THE GST'S COMPONENTS (CONT.)}

\section{Component 1: Information collection and preparation \\ Ensuring that the information collected is robust and of good quality will be critical in the first component: \\ - Additional guidance is needed regarding the source and type of information required to ensure that the GST assesses the breadth of its scope, in spite of potential data gaps. \\ - Such guidance could be provided by SBSTA.}

Component 3: Consideration of outputs

\section{SOURCES OF INPUT}

\section{CROSS-CUTTING ISSUES}

Thorough technical analysis will be required in the second component to digest and analyze the wealth of information coming from the first component and produce output that is politically relevant for the third component to consider. For this, indicators will be required.

There are crucial intersections between the choice of indicators that will bring more granularity to the GST and the need for the GST's assessments to reflect equity. This issue brief suggests the following:

- Indicator selection can happen at the start of the technical dialogue, during the IPCC-SBSTA dialogue mandated by the Katowice decision.

- Indicators could build in equity, bring in the societal perspective as well as CBDR.

- Group countries into tiers according to indicators of responsibility and capability.

- Draw on Parties' explanations of equity incorporated in their NDCs, aggregating those into a commonly accepted framework for recognizing the fairness and adequacy of a contribution.

\section{OUTPUTS}


MATCHING SUGGESTIONS FOR AN EFFECTIVE GST TO THE GST'S COMPONENTS (CONT.)

\section{Component 1: Information collection and} preparation
Component 2: Technical assessment

OUTPUTS (CONT.)

\section{PARTICIPATION AND ENGAGEMENT IN THE GST}

- Refining mechanisms to identify and redress information gaps during the first component can ensure that if the information collected by the cutoff date is not reflective of balance and equity, additional information can be gathered. This will ensure that the information collected is not heavily dominated by developed countries.

- Involving line ministries in this component beyond the environment ministries will ensure that the data collected are comprehensive.

- Encouraging the convening of national, regional, and thematic dialogues on information collection outside the official GST in this component can help countries harvest the information and data they require.

- Setting up a fair supporting process to facilitate the identification of relevant non-Party stakeholders as participants in the first component would help screen the increasingly large volume of information generated outside the UNFCCC, and provide opportunities for stakeholders to review, comment, and complement the input.

- Holding convenings to engage international institutions in the process of gathering information relevant to the GST.
- Encouraging the convening of national, regional, and thematic GST-related technical dialogues outside the official GST technical dialogue can ensure that the large volume of information collected in the first component is comprehensively assessed.

- Involving line ministries in the GST beyond the environment ministries can ensure that the thematic expertise required for the technical dialogue is secured.

- Setting up a fair supporting process to facilitate the identification of relevant non-Party stakeholders as participants to the technical dialogue would secure the thematic expertise for the technical analysis required under the technical dialogue. This would also ensure opportunity for discussion between technical and political actors.

- Holding convenings with international institutions to secure their participation in assessing collective progress on climate action and opportunities to strengthen that action in their fields.
Component 3: Consideration of outputs



Translating outputs into outcomes: The time between the end of the GST and the start of the COP by when announcements of updated and enhanced NDCs are expected should be used to ensure that the outputs of the GST are translated into the desired outcomes. To tap opportunities within this timeframe, this issue brief suggests:

- building political momentum within the GST process that can be carried over into the national NDC revision processes; and

- leveraging other technical and political processes at the national and international levels to ensure that the GST becomes nationally relevant. This includes greater interaction with other international institutions to appraise the findings of the GST in different regions and sectors.

- Securing high-level participation in the third component of the GST to ensure that the GST outputs are taken up at the national level and translated as concrete ambition, as appropriate, in different national contexts. This would also give a strong renewed political signal of commitment to the PA.

- Involve line ministries in the GST beyond the environment ministries to secure the thematic expertise required to discuss the implications of the findings of the technical assessment.

- Set up a fair supporting process to facilitate the identification of relevant non-Party stakeholders as participants in the third component. This would ensure opportunity for discussion between technical and political actors beyond the nine constituencies currently under the UNFCCC which are those generally represented during the COPS.

- Invite international institutions to be represented in the high-level dialogue between stakeholders and Parties suggested under "Making the Outputs Politically Impactful" section of this issue brief. 


\section{ABBREVIATIONS}

AR

BA

BTR

CBDR-RC

CMA

COP

ETF

FAO

GST

HoSGs

iGST

IMF
Assessment Report

Biennial Assessment and Overview of Climate

Finance Flows

Biennial Transparency Report

Common but Differentiated Responsibilities

and Respective Capabilities

Conference of the Parties serving as the Meeting

of the Parties to the Paris Agreement

Conference of the Parties

Enhanced Transparency Framework

Food and Agriculture Organization

Global Stocktake

Heads of state and government

Independent Global Stocktake

International Monetary Fund
IMO

IPCC

NAP

NDC

NIR

PA

SB

SBI

SBSTA

SYR

UNFCCC

WHO
International Maritime Organization

Intergovernmental Panel on Climate Change

National Adaptation Plan

Nationally Determined Contribution

National Inventory Report

Paris Agreement

Subsidiary Body

Subsidiary Body for Implementation

Subsidiary Body for Scientific and

Technological Advice

Synthesis Report

United Nations Framework Convention on Climate Change

World Health Organization 


\section{ENDNOTES}

1. This includes the global goals under the Paris Agreement, but also other commitments stipulated in the agreement, such as NDCs and finance.

2. The Global Climate Action Agenda was originally launched as the LimaParis Action Agenda in 2014 as an initiative to mobilize global climate action and boost cooperation across multiple stakeholders.

3. The long-term mitigation goals referred to in the Paris Agreement include Article 2.1(a): "This Agreement, [...] aims to strengthen the global response to the threat of climate change [...] including by: Holding the increase in the global average temperature to well below $2^{\circ} \mathrm{C}$ above pre-industrial levels and pursuing efforts to limit the temperature increase to $1.5^{\circ} \mathrm{C}$ above pre-industrial levels, recognizing that this would significantly reduce the risks and impacts of climate change" and Article 4.1: "In order to achieve the long-term temperature goal set out in Article 2, Parties aim to reach global peaking of greenhouse gas emissions as soon as possible, recognizing that peaking will take longer for developing country Parties, and to undertake rapid reductions thereafter in accordance with best available science, so as to achieve a balance between anthropogenic emissions by sources and removals by sinks of greenhouse gases in the second half of this century, on the basis of equity, and in the context of sustainable development and efforts to eradicate poverty."

4. The long-term adaptation goal in the Paris Agreement refers to Article 2.1(b): "This Agreement, [...] aims to strengthen the global response to the threat of climate change [...] including by: Increasing the ability to adapt to the adverse impacts of climate change and foster climate resilience and low greenhouse gas emissions development, in a manner that does not threaten food production."

5. The long-term finance goal in the Paris Agreement refers to Article 2.1(c): "This Agreement, [...] aims to strengthen the global response to the threat of climate change [...] including by: Making finance flows consistent with a pathway towards low greenhouse gas emissions and climate-resilient development."

6. As per Article 4.3 of the Paris Agreement, Parties' successive NDCs will represent a progression beyond the previous NDC and reflect the highest possible ambition.

7. Decision $19 / C M A .1$.

8. Paragraph 6.B of 19/CMA.1.

9. While this issue brief organizes the gaps into those related to process and those related to content, Appendix C matches the suggestions made in this issue brief to the different components of the GST.

10. Under SBSTA.
11. The organizations currently part of the iGST are the Climate Equity Reference Project, ClimateWorks Foundation, the NewClimate Institute, the Overseas Development Institute, UNEP DTU Partnership, the University of Maryland Center for Global Sustainability, the World Resources Institute, and the Wuppertal Institute.

12. Specifically, the Structured Expert Dialogues and the Talanoa Dialogue.

13. Paragraph 4 of 19/CMA.1.

14. Paragraph 8 of 19/CMA.1 states that the technical assessment component of the GST will start a year to a year and a half-depending on the timing of the publication of the IPCC reports-before COP at which the consideration of outputs components is to take place (November 2023, in the case of the first GST). In the case of the first GST, the IPCC AR6 Working Group and the SYRs are due for completion by July 2022, meaning that the technical assessment could commence at the SB session scheduled right after in December 2022, and that the information collection component could start at the SB session six months prior to that, in June 2022. This means that the first GST would unroll over 18 months. However, future GSTs may unroll over 18 to 24 months, depending on the timing of the publication of future IPCC reports, which is unknown to date.

15. For a detailed timeline of the first GST, see Appendix A.

16. The SBs can also decide to incorporate additional inputs as per paragraphs 25 and 38 of 19/CMA.1.

17. Currently, the constituted bodies and forums are the Adaptation Committee, the Least Developed Country Expert Group, the Technology Executive Committee, the Standing Committee on Finance, the Paris Committee on Capacity-building, the Executive Committee of the Warsaw International Mechanism for Loss and Damage associated with Climate Change Impacts, the Consultative Group of Experts, the forum on the impact of the implementation of response measures, and the Local Communities and Indigenous Peoples Platform Facilitative Working Group.

18. Paragraph 37.i of 19/CMA.1.

19. Paragraph 36 of 19/CMA.1 establishes that those themes are (i) GHG emissions by sources and removals by sinks, and mitigation efforts undertaken by Parties; (ii) overall effect of NDCs and overall implementation progress made by Parties; (iii) the state of adaptation efforts, support, experience, and priorities; (iv) finance flows, means of implementation and support, and the mobilization and provision of support; (v) efforts on loss and damage; (vi) barriers and challenges faced by developing countries; (vii) good practices and opportunities to enhance international climate cooperation; and (viii) fairness considerations as communicated by Parties in their NDCs. 
20. Negotiation during the meetings of the subsidiary bodies SBTSA and SBI.

21. Paragraphs 8,19 , and 20 of $19 /$ CMA.1.

22. One from a developing country Party and one from a developed country Party selected by Parties.

23. The constituted bodies under the PA are also invited to provide SYRs on those themes in their areas of expertise (Paragraph 24 of 19/CMA.1).

24. Paragraph 8 of $19 / C M A .1$.

25. Over two or three SB sessions, depending on the timing of the publication of the IPCC reports as per paragraph 8 of 19/CMA.1. With Component 1 potentially ending six months before Component 3 , there is the potential for considerable overlap between Components 1 and 2 .

26. Paragraph 8 of $19 /$ CMA.1.

27. Paragraph 31 of $19 /$ CMA.1.

28. Could be in the form of a COP decision.

29. These events will be chaired by the Presidencies of the COP serving as the meeting of the Parties to the Paris Agreement (CMA) and by the Chairs of the Subsidiary Bodies (Paragraph 33 of 19/CMA.1).

30. Paragraph 34(a-c) of 19/CMA.1.

31. The GST could shed some light on how to achieve a balanced provision of finance for mitigation and adaptation, and what an adequate adaptation response could be by showing that the current level of adaptation action is insufficient. It could cultivate the knowledge required to develop an understanding of the policies and support required to be consistent with the PA's long-term goals by assessing finance flows and means of implementation and support.

32. As per Article 7.4 of the Paris Agreement.

33. Decisions 3 to 20/CMA.1 of the Katowice decision.

34. Paragraph 14 of $19 /$ CMA.1.

35. Paragraph 6(b) of 19/CMA.1.

36. Paragraph 7 of $19 /$ CMA.1.
37. An IPCC cycle comprises the Assessment Reports, the Synthesis Report, and the Special Reports.

38. BTRs shall include the following information: national GHG inventories, progress made on NDC implementation, finance, technology-transfer, and capacity building. Information related to climate impacts and adaptation can be voluntarily included in these reports (Dagnet et al. 2019).

39. Non-Annex 1 Parties (which are mostly developing countries) should submit their first BURs by December 2014, and every two years after that, with Least Developed Countries (LDCs) and Small Island Developing States (SIDSs) to submit them at their own discretion. Thirty-six percent of non-Annex 1 Parties submitted their BUR1, 20 percent submitted their BUR2, and 6 percent have submitted their BUR3.

40. Paragraph 19 of $19 /$ CMA.1.

41. Paragraph 6(c) of 19/CMA.1.

42. Paragraph 11 of $19 /$ CMA.1.

43. Paragraph 12 of $19 /$ CMA.1.

44. Paragraph 37(i) of 19/CMA.1.

45. Paragraphs 37(f) and 37(h) of 19/CMA.1.

46. Paragraph 34 of $19 /$ CMA.1.

47. See "Participation and Engagement in the GST" section of this issue brief to refine the mechanisms in the Katowice decision that provide openings to identify and redress data gaps.

48. This issue brief will not go in depth on the potential role of the constituted bodies in the GST. Further research will be needed.

49. Article 2.1(b) states that the PA aims to strengthen the global response to the threat of climate change, including by: "Increasing the ability to adapt to the adverse impacts of climate change and foster climate resilience and low greenhouse gas emissions development, in a manner that does not threaten food production"; and Article 7.1 of the PA states: "Parties hereby establish the global goal on adaptation of enhancing adaptive capacity, strengthening resilience and reducing vulnerability to climate change, with a view to contributing to sustainable development and ensuring an adequate adaptation response in the context of the temperature goal referred to in Article 2."

50. Under Article 7.1 of the PA. 
51. Article 7.7 of the PA states that "Parties should strengthen their cooperation on enhancing action on adaptation, taking into account the Cancun Adaptation Framework, including with regard to: (a) Sharing information, good practices, experiences and lessons learned, including, as appropriate, as these relate to science, planning, policies, and implementation in relation to adaptation actions; (b) Strengthening institutional arrangements, including those under the Convention that serve this Agreement, to support the synthesis of relevant information and knowledge, and the provision of technical support and guidance to Parties; (c) Strengthening scientific knowledge on climate, including research, systematic observation of the climate system and early warning systems, in a manner that informs climate services and supports decision-making; (d) Assisting developing country Parties in identifying effective adaptation practices, adaptation needs, priorities, support provided and received for adaptation actions and efforts, and challenges and gaps, in a manner consistent with encouraging good practices; and (e) Improving the effectiveness and durability of adaptation actions."

52. Article 7.6 of the PA states: "Parties recognize the importance of support for and international cooperation on adaptation efforts and the importance of taking into account the needs of developing country Parties, especially those that are particularly vulnerable to the adverse effects of climate change."
53. Article 7.5 of the PA states: "Parties acknowledge that adaptation action should follow a country-driven, gender-responsive, participatory and fully transparent approach, taking into consideration vulnerable groups, communities and ecosystems, and should be based on and guided by the best available science and, as appropriate, traditional knowledge, knowledge of indigenous peoples and local knowledge systems, with a view to integrating adaptation into relevant socioeconomic and environmental policies and actions, where appropriate."

54. Authors recognize that if adaptation actions and related spending become mainstreamed into various development agenda, it will make it more difficult to identify what sectoral efforts are deemed "adaptation" and, therefore, to distinguish (disaggregate) adaptation spending from broader sectoral spending. Hence, there is a need for more guidance on metrics and approaches to be used by Parties.

55. Paragraph 1 of $19 /$ CMA.1.

56. While not trespassing on the GST's mandate to assess collective progress in a way that does not single out individual countries.

57. Paragraph 27 of 19/CMA.1.

58. Paragraph 29 of $19 /$ CMA.1.

59. Paragraph 6.a of 19/CMA.1. 


\section{REFERENCES}

Al-Zahrani, Heshame, Chai Qimin, Fu Sha, Yaw Osafo, Adriano Santhiago de Oliveira, Anushree Tripathi, Harald Winkler, and Vicente Paolo Yu III. 2019. "Ensuring an Operational Equity-Based Global Stocktake under the Paris Agreement." Research Paper 99, South Centre, September. https:// www.southcentre.int/wp-content/uploads/2019/09/RP99_Ensuring-anOperational-Equity-Based-Global-Stocktake-under-the-Paris-Agreement-_ EN.pdf.

Beuermann, Christiane, Wolfgang Obergassel, and Hanna Wang-Helmreich. 2020. "Design Options for the Global Stocktake: Lessons from Other Review Processes." Wuppertal Institute. Part of the iGST Designing a Robust Stocktake Discussion Series. https://www.climateworks.org/wp-content/ uploads/2020/05/Design-Options-for-the-Global-Stocktake_iGST_ Wuppertal.pdf.

Christiansen, Lars, Anne Olhoff, and Thomas Dale. 2020. "Understanding Adaptation in the Global Stocktake." UNEP DTU Partnership. Part of the iGST Designing a Robust Stocktake Discussion Series, https://www. climateworks.org/wp-content/uploads/2020/05/Understanding-Adaptationin-the-Global-Stocktake_iGST_UNEP-DTU.pdf.

Clark, Leon, and Nathan Hultman. 2020. "Mitigation Information and the Independent Global Stocktake." Center for Global Sustainability, School of Public Policy, University of Maryland. Part of the iGST Designing a Robust Stocktake Discussion Series. https://www.climateworks.org/wp-content/ uploads/2020/05/Mitigation-Information-and-the-Independent-GlobalStocktake_iGST_UMD-Center-for-Global-Sustainability.pdf.

Cogswell, Nathan, and Yamide Dagnet. 2019. "Explaining the Paris Agreement Rulebook." World Resources Institute. https://wriorg.s3.amazonaws.com/ s3fs-public/unpacking-paris-agreement-rulebook.pdf.

Dagnet, Yamide, Nathan Cogswell, Neil Bird, Mathilde Bouyé, and Marcelo Rocha. 2019. "Building Capacity for the Paris Agreement's Enhanced Transparency Framework: What Can We Learn from Countries' Experiences and UNFCCC Processes?" Working Paper. Washington, DC: Project for Advancing Climate Transparency (PACT), https://www.wri.org/publication/ capacity-building-paris-transparency.

Gupta Sujata, Jochen Harnisch, Dipal Chandra Barua, Lloyd Chingambo, Paul Frankel, Raúl Jorge Garrido Vázquez, Luis Gómez-Echeverri, et al. 2014. "Cross-cutting Investment and Finance Issues." In Climate Change 2014: Mitigation of Climate Change. Working Group III Contribution to the Fifth Assessment Report of the Intergovernmental Panel on Climate Change, edited by Ottmar Edenhofer, Ramón Pichs-Madruga, Youba Sokona, Ellie Farahani, Susanne Kadner, Kristin Seyboth, Anna Adler, et al. Cambridge and New York: Cambridge University Press. https://www.ipcc.ch/site/assets/ uploads/2018/02/ipcc_wg3_ar5_full.pdf.

Holz, Christian, Tom Athanasiou, and Sivan Kartha. 2019. "Equity in the Global Stocktake and Independent Global Stocktake." iGST Designing a Robust Stocktake Discussion Series. Berkeley, Boston, Ottawa: Climate Equity Reference Project. https://doi.org/10.5281/zenodo.2595493.
Höhne, Niklas, Louise Jeffery, Anna Nilsson, and Hanna Fekete. 2019. "Guiding Questions for the Global Stocktake under the Paris Agreement: What We Know and What We Don't." NewClimate Institute. Part of the iGST Designing a Robust Stocktake Discussion Series. https://www.climateworks.org/ wp-content/uploads/2020/05/Guiding-Questions-for-the-Global-Stocktake_ iGST_NewClimate.pdf.

Jeffrey, Louise, Anne Siemons, and Lukas Hermwille. 2019. "Tackling the Challenge of Assessing Collective Progress for an Effective Global Stocktake: Executive Summary." Germany: Federal Ministry for the Environment, Nature Conservation and Nuclear Safety. https://newclimate.org/wp-content/ uploads/2019/11/ExecutiveSummary_Tackling_Challenges_Global_ Stocktake.pdf.

Northrop, Eliza, Yamide Dagnet, Niklas Höhne, Joe Thwaites, and Kathleen Mogelgaard. 2018. "Achieving the Ambition of Paris: Designing the Global Stocktake." Working Paper. Washington, DC: Project for Advancing Climate Transparency (PACT). https://www.wri.org/publication/pact-globalstocktake-design.

Obergassel, Wolfgang, Lukas Hermwille, Anne Siemons, and Hannah Förster. 2019. "Success Factors for the Global Stocktake under the Paris Agreement." Wuppertal Institute. Part of the iGST Designing a Robust Stocktake Discussion Series, https://www.climateworks.org/wp-content/ uploads/2020/05/Success-Factors-for-the-Global-Stocktake_iGST_ Wuppertal.pdf.

UNFCCC (United Nations Framework Convention on Climate Change). 2015. "The Paris Agreement." https://unfccc.int/process-and-meetings/the-parisagreement/the-paris-agreement.

UNFCCC. 2018. "Matters Relating to Article 14 of the Paris Agreement and Paragraphs 99-101 of Decision 1/CP.21." FCCC/PA/CMA/2018/3/Add.2. https:// unfccc.int/sites/default/files/resource/cma2018_3_add2_new_advance. pdf\#page $=53$.

Watson, Charlene, and Leo Roberts. 2019. "Understanding Finance in the Global Stocktake." Overseas Development Institute. Part of the iGST Designing a Robust Stocktake Discussion Series. https://www. climateworks.org/wp-content/uploads/2020/05/Understanding-Finance-inthe-Global-Stocktake_iGST_ODI.pdf.

Whitley, Shelagh, Joe Thwaites, Helena Wright, and Caroline 0tt. 2018. "Making Finance Consistent with Climate Goals: Insights for Operationalizing Article 2.1c of the UNFCCC Paris Agreement." Overseas Development Institute. https://www.odi.org/sites/odi.org.uk/files/resourcedocuments/12557.pdf.

Winkler, Harald. 2020. "Putting Equity into Practice in the Global Stocktake under the Paris Agreement." Climate Policy 20 (1): 124-132, D0l: 10.1080/14693062.2019.1680337.

WRI (World Resources Institute). 2020. "Navigating the Paris Agreement Rulebook: Global Stocktake." https://www.wri.org/paris-rulebook/globalstocktake. 


\section{ACKNOWLEDGMENTS}

The authors would like to acknowledge and thank the ClimateWorks Foundation, which provided funding and guidance for the World Resources Institute's work on the Independent Global Stocktake (iGST).

The authors would also like to acknowledge WRI's institutional strategic partners who provide core funding: the Netherlands' Ministry of Foreign Affairs, the Royal Danish Ministry of Foreign Affairs, and the Swedish International Development Cooperation Agency.

The authors also thank the IKEA Foundation for their financial support of this publication.

The authors are grateful to the following member organizations of the iGST for their contributions and insights, which have helped shape this issue brief: the Climate Equity Reference Project, the NewClimate Institute, the Overseas Development Institute, UNEP DTU Partnership, the University of Maryland School of Public Policy Center for Global Sustainability, and the Wuppertal Institute.

The authors acknowledge the following WRI reviewers whose thoughtful comments, suggestions, insights, and wide-ranging expertise helped make this issue brief more robust and balanced: Subrata Chakrabarty, Christina Chan, Nathan Cogswell, Johannes Friedrich, David Gibbs, Lorena Gonzalez, and Eliza Northrop.

The authors also acknowledge the external reviewers who provided further comments and insights to strengthen the paper, including Prof. Chukwumerije Okereke, Rixa Schwarz, Nilesh Prakash, and others who wished to remain anonymous.

Finally, the authors thank those who have contributed to the design, structure, editing, and production of this paper: Meg Beiter, Tim Constien, Emily Matthews, Emilia Suarez, Romain Warnault, and David Waskow.

\section{ABOUT THE AUTHORS}

Yamide Dagnet is the director of Climate Negotiations at the World Resources Institute and a part-time senior country engagement specialist at the NDC Partnership.

Contact: ydagnet@wri.org.

Noëmie Leprince-Ringuet is the current head of the Technical Support Unit for the Intergovernmental Panel on Climate Change's Synthesis Report of the Sixth Assessment Report. She is a former associate in the Global Climate Program of the World Resources Institute.

Contact: noemie.leprinceringuet@ipcc-syr.org.

Jemima Marie Mendoza is a research analyst in the International Climate Action initiative at the World Resources Institute. Contact: jemima.mendoza@wri.org.

Joe Thwaites is an associate in the Sustainable Finance Center at the World Resources Institute.

Contact: joe.thwaites@wri.org.

\section{PHOTO CREDITS}

Cover, Yann Caradec; Pg. 2, UNclimatechange; Pg. 17, Lewis Parsons. 


\section{ABOUT WRI}

World Resources Institute is a global research organization that turns big ideas into action at the nexus of environment, economic opportunity and human well-being.

\section{Our Challenge}

Natural resources are at the foundation of economic opportunity and human well-being. But today, we are depleting Earth's resources at rates that are not sustainable, endangering economies and people's lives. People depend on clean water, fertile land, healthy forests, and a stable climate. Livable cities and clean energy are essential for a sustainable planet. We must address these urgent, global challenges this decade.

\section{Our Vision}

We envision an equitable and prosperous planet driven by the wise management of natural resources. We aspire to create a world where the actions of government, business, and communities combine to eliminate poverty and sustain the natural environment for all people.

\section{ABOUT THE IGST INITIATIVE}

The Independent Global Stocktake (iGST) is an umbrella data and advocacy initiative that brings together climate modelers, analysts, campaigners, and advocates to support the Paris Agreement. www.climateworks.org/independentglobalstocktake/.

The Designing a Robust Stocktake Discussion Series envisions the contours of an ideal Global Stocktake and suggests ways in which the independent community can help to achieve that vision. These papers were produced by iGST partner organizations in consultation with the broader community, but the views expressed are the authors' own and don't necessarily reflect those of the iGST initiative or associated partner organizations.

Each World Resources Institute issue brief represents a timely, scholarly treatment of a subject of public concern. WRI takes responsibility for choosing the study topics and guaranteeing its authors and researchers freedom of inquiry. It also solicits and responds to the guidance of advisory panels and expert reviewers. Unless otherwise stated, however, all the interpretation and findings set forth in WRI publications are those of the authors.

Maps are for illustrative purposes and do not imply the expression of any opinion on the part of WRI, concerning the legal status of any country or territory or concerning the delimitation of frontiers or boundaries.




WORLD

RESOURCES

I NST I T U T E

$10 \mathrm{G}$ STREET NE

SUITE 800

WASHINGTON, DC 20002, USA

+1 (202) 729-7600

WWW.WRI.ORG 